\title{
Complementation of CTB7 in the Maize Pathogen Cercospora zeina Overcomes the Lack of In Vitro Cercosporin Production
}

\author{
Velushka Swart, ${ }^{1}$ Bridget G. Crampton, ${ }^{1}$ John B. Ridenour, ${ }^{2}$ Burt H. Bluhm, ${ }^{2}$ Nicholas A. Olivier, ${ }^{1}$ \\ J. J. Marion Meyer, ${ }^{3}$ and Dave K. Berger ${ }^{1,+}$ \\ ${ }^{1}$ Department of Plant and Soil Sciences, Forestry and Agricultural Biotechnology Institute (FABI), Genomics Research Institute, \\ University of Pretoria, Private Bag x20, Hatfield 0028, South Africa; ${ }^{2}$ Department of Plant Pathology, University of Arkansas, \\ Fayetteville, AR 72701, U.S.A.; and ${ }^{3}$ Department of Plant and Soil Sciences, University of Pretoria
}

Accepted 17 May 2017.

\begin{abstract}
Gray leaf spot (GLS), caused by the sibling species Cercospora zeina or Cercospora zeae-maydis, is cited as one of the most important diseases threatening global maize production. $C$. zeina fails to produce cercosporin in vitro and, in most cases, causes large coalescing lesions during maize infection, a symptom generally absent from cercosporin-deficient mutants in other Cercospora spp. Here, we describe the $C$. zeina cercosporin toxin biosynthetic $(C T B)$ gene cluster. The oxidoreductase gene $C T B 7$ contained several insertions and deletions as compared with the C. zeae-maydis ortholog. We set out to determine whether complementing the defective $C T B 7$ gene with the full-length gene from $C$. zeae-maydis could confer in vitro cercosporin production. C. zeina transformants containing $C$. zeae-maydis CTB7 were generated by Agrobacterium tumefaciens-mediated transformation and were evaluated for in vitro cercosporin production. When grown on nitrogen-limited medium in the light—conditions conducive to cercosporin production in other Cercospora spp.--one transformant accumulated a red pigment that was confirmed to be cercosporin by the KOH assay, thin-layer chromatography, and ultra performance liquid chromatography-quadrupoletime-of-flight mass spectrometry. Our results indicated that $C$. zeina has a defective $C T B 7$, but all other necessary machinery required for synthesizing cercosporin-like molecules and, thus, C. zeina may produce a structural variant of cercosporin during maize infection.
\end{abstract}

Gray leaf spot (GLS) continues to be a devastating maize foliar disease of global importance that has resulted in extensive yield losses over the past few decades (Crous and Braun 2003; Ward et al. 1999). Previously classified as Cercospora zeae-maydis Group I and Group II, the causative agents of GLS, C. zeae-maydis and Cercospora zeina are differentiated by both

Cercospora zeina sequence data is deposited in the DDBJ/EMBL/GenBank database under the accession number KY656140. The raw RNA-seq reads are deposited under the Genome Expression Omnibus accessions GSE90705 and GSE94442.

${ }^{\dagger}$ Corresponding author: D. K. Berger; E-mail: Dave.Berger@up.ac.za

*The $\boldsymbol{e}$-Xtra logo stands for "electronic extra" and indicates that three supplementary files, six supplementary figures, and one supplementary table are published online.

(c) 2017 The American Phytopathological Society genetic distance and phenotypic characteristics, such as their ability to produce the phytotoxin cercosporin (Crous et al. 2006; Goodwin et al. 2001). Cercospora zeina predominates throughout Africa, while C. zeae-maydis is most prevalent in the majority of the United States and Mexico (Dunkle and Levy 2000; Goodwin et al. 2001; Meisel et al. 2009; Wang et al. 1998).

The genus Cercospora is part of the class Dothideomycetes and consists of more than 600 recognized species of plant pathogens (Crous and Braun 2003). Although Cercospora species generally exhibit relatively narrow host ranges, many produce cercosporin, a photosensitizing perylenequinone that functions as a nonspecific toxin that has been identified as a major pathogenicity factor (Daub and Ehrenshaft 2000; Weiland et al. 2010). Cercosporin production has been demonstrated for several Cercospora species, with isolates of C. kikuchii, C. beticola, C. zeae-maydis, C. asparagi, and $C$. nicotianae all shown to accumulate cercosporin in vitro (Jenns et al. 1989). Isolates of C. zeina, however, demonstrate a lack of cercosporin production in vitro (Dunkle and Levy 2000; Goodwin et al. 2001; Koshikumo et al. 2014). These species all cause leaf spot diseases that are characterized by severe blighting of leaves (Daub and Ehrenshaft 2000). In contrast to this, isolates of the peanut pathogen C. arachidicola fail to produce cercosporin and induce only small chlorotic lesions (Fore et al. 1988). Isolates of C. arachidicola have, however, been shown to produce other toxins that may aid in virulence (Fore et al. 1988).

Once activated by visible wavelengths of light, cercosporin functions by producing reactive oxygen species (ROS), such as singlet oxygen and superoxide radicals, that cause oxidative damage to a wide range of macromolecules (Daub and Chung 2009; Daub and Ehrenshaft 2000). Cercosporin is thought to damage plant host cells primarily by inducing oxidative deterioration of lipids within cell membranes; the subsequent leakage of nutrients creates a favorable environment for the growth and sporulation of Cercospora spp., which culminates in host cell death (Daub and Chung 2009; Daub and Ehrenshaft 2000). Production of cercosporin during plant colonization has thus been linked to large, coalescing lesions in some Cercospora infections, whereas studies have demonstrated the induction of only small, necrotic flecks in cercosporin-deficient isolates (Choquer et al. 2005; Upchurch et al. 1991).

Cercosporin biosynthesis mainly involves a cluster of eight cercosporin toxin biosynthetic $(C T B)$ genes, all of which are transcriptionally induced upon exposure to light in the tobacco pathogen $C$. nicotianae (Chen et al. 2007b). Targeted disruption of any $C T B$ gene blocked cercosporin production and reduced 
virulence in planta (Chen et al. 2007a and b; Choquer et al. 2005, 2007; Dekkers et al. 2007). CTB8 encodes a Zn(II)Cys 6 transcriptional activator that coordinates expression of the $C T B$ genes under appropriate conditions for cercosporin production (Chen et al. 2007b), while CTB4 encodes a major facilitator superfamily transporter protein involved in cercosporin export (Choquer et al. 2007). The six remaining CTB genes (CTB1, CTB2, CTB3, CTB5, CTB6, and CTB7) function directly in cercosporin biosynthesis. Although the biochemical pathway underlying cercosporin biosynthesis has not been fully elucidated, metabolic profiling of individual $C$. nicotianae CTB knockout strains has resolved key components of cercosporin biosynthesis (Newman and Townsend 2016).

We hypothesized that there may be an underlying genetic cause for the lack of cercosporin production in $C$. zeina. Here, we present the identification and annotation of the $C T B$ gene cluster in $C$. zeina as well as evidence of coding sequence degradation for the $C T B 7$ gene, as compared with its orthologs in $C$. zeae-maydis and $C$. nicotianae. Truncation of the $C$. zeina CTB7 gene due to the presence of indels was found to be common to $C$. zeina isolates from different African countries and the United States. The $C$. zeina $C T B 7$ gene region was not transcribed in vitro and exhibited incomplete splicing in planta. Agrobacterium tumefaciens-mediated transformation was used to complement $C$. zeina with the $C$. zeae-maydis CTB7 gene copy. Chemical analysis demonstrated cercosporin production under the appropriate in vitro growth conditions in one of the $C$. zeina $C z m C T B 7$ transformants. Our evidence suggests that $C T B 7$ is a pseudogene responsible for the lack of cercosporin production in C. zeina.

\section{RESULTS}

C. zeina fails to produce cercosporin in vitro.

Cercospora zeina CMW25467 from Zambia (Table 1) did not produce the visible red compound cercosporin when grown in vitro on nitrogen-limiting medium $(0.2 \times$ potato dextrose agar [PDA]) (Fig. 1A). Similarly, the United States isolate of C. zeina (OYPA, USPA-4) was cercosporin negative in vitro, as reported for all African and the United States C. zeina isolates tested previously (Dunkle and Levy 2000) (Fig. 1A). This was in contrast to the profuse cercosporin production by C. zeae-maydis SCOH1-5 (Fig. 1A), a second fungal species that causes gray leaf spot disease of maize (Bluhm et al. 2008).

\section{C. zeina CMW25467 harbors an intact $C T B$ gene cluster, except for $C T B 7$.}

We exploited the availability of the C. zeina CMW25467 genome sequence (Muller et al. 2016) to determine whether the $C T B$ gene cluster was absent or defective. BLAST analysis using the $C$. nicotianae $C T B$ gene sequences as queries revealed a $C T B$ gene cluster on a single $C$. zeina contig (with $E$ values of 0.0 for $C T B 1, C T B 3, C T B 5$, and CTB6). CTB gene models were annotated in silico, using i) gene prediction programs (AUGUSTUS, FGENESH and SNAP) and ii) RNA-seq reads from in vitro-grown $C$. zeina cultures. The predicted $C$. zeina $C T B$ genes had best BLASTx matches corresponding to the C. nicotianae CTB protein sequences (Table 2), and pairwise alignments showed amino acid identities of 85 to $90 \%$ for CTB1 to CTB6, 68\% identity for CTB8 (Supplementary File S1), but only $51 \%$ identity for CTB7 (Table 2). In silico annotation of the $C$. zeina $C T B 7$ gene region in the absence of in vitro transcript sequence data predicted a single intron and a putative CTB7 polypeptide of 322 amino acids, which was considerably shorter than the $C$. nicotianae 450-amino acid CTB7 (Chen et al. 2007b). The order and orientation of the predicted $C$. zeina $C T B$ genes (Fig. 1B) was the same as the $C$. nicotianae $C T B$ cluster reported previously (Chen et al. 2007b). Transcripts were detected for all of the $C$. zeina $C T B$ genes except $C T B 7$, under seven different in vitro growth conditions (Table 3 ).

Table 1. Cercospora isolates utilized in this study

\begin{tabular}{|c|c|c|c|}
\hline Species $^{\mathbf{a}}$ & Isolate $^{\mathbf{b}}$ & Area, country of isolation & Reference \\
\hline C. zeina & CMW25467 & Mkushi, Zambia & Meisel et al. 2009 \\
\hline C. zeina & 2011.GT30 & KwaZulu-Natal, South Africa & Muller et al. 2016 \\
\hline C. kikuchii & CMW49223 & KwaZulu-Natal, South Africa & \\
\hline C. zeina & NLUG 1.23 (B9-P9) ${ }^{\mathrm{d}}$ & Uganda & \\
\hline C. zeina & NLUG 1.23 (B9-P11) ${ }^{\mathrm{d}}$ & Uganda & \\
\hline C. zeina & NLUG 1.23 (B9-P12) ${ }^{\mathrm{d}}$ & Uganda & \\
\hline C. zeina & NLUG 1.23 R (B9-P20) ${ }^{\mathrm{d}}$ & Uganda & \\
\hline C. zeina & Zambia (B9-P16) ${ }^{\mathrm{d}}$ & Zambia & \\
\hline C. zeina & Zambia 3.2 (B9-P26) ${ }^{\mathrm{d}}$ & Zambia & \\
\hline C. zeina & Zambia 3.2 (B9-P31) ${ }^{\mathrm{d}}$ & Zambia & \\
\hline C. zeina & Zambia 3.2 (B9-P32) & Zambia & \\
\hline C. zeina & CMNY C2 (B8-P1) ${ }^{\mathrm{d}}$ & New York, U.S.A. & \\
\hline C. zeina & CMNY C2 (B8-P3) ${ }^{\mathrm{d}}$ & New York, U.S.A. & \\
\hline C. zeina & CMNY C2 (B8-P2) ${ }^{\mathrm{d}}$ & New York, U.S.A. & \\
\hline C. zeina & WOOH-NCR (B8-P25) ${ }^{\mathrm{d}}$ & Ohio, U.S.A. & \\
\hline C. zeina & WOOH-NCR (B8-P26) ${ }^{\mathrm{d}}$ & Ohio, U.S.A. & \\
\hline C. zeina & WOOH-NCR (B8-P27) ${ }^{\mathrm{d}}$ & Ohio, U.S.A. & \\
\hline C. zeina & WOOH-NCR (B8-P28) ${ }^{\mathrm{d}}$ & Ohio, U.S.A. & \\
\hline C. zeina & OYPA $16($ B8-P5) & Pennsylvania, U.S.A. & \\
\hline C. zeina & OYPA $16\left(\right.$ B8-P7) ${ }^{\mathrm{d}}$ & Pennsylvania, U.S.A. & \\
\hline C. zeina & OYPA $16\left(\right.$ B8-P9) ${ }^{\mathrm{d}}$ & Pennsylvania, U.S.A. & \\
\hline C. zeae-maydis & CBS 117757 & Wisconsin, U.S.A. & Crous et al. 2006 \\
\hline C. zeae-maydis & CBS 117761 & Indiana, U.S.A. & Crous et al. 2006 \\
\hline C. zeae-maydis & $\mathrm{SCOH} 1-5^{\mathrm{d}}$ & Ohio, U.S.A. & Bluhm et al. 2008 \\
\hline
\end{tabular}

${ }^{a}$ Based on diagnostic histone gene polymerase chain reaction analysis (Crous et al. 2006).

${ }^{\mathrm{b}} \mathrm{CMW}=$ Culture collection of the Forestry and Agricultural Biotechnology Institute, University of Pretoria, South Africa. CBS = Culture collection of the Centraalbureau voor Schimmelcultures, Utrecht, The Netherlands.

c Isolated by V. Coetzee from a soybean leaf with symptoms of Cercospora leaf blight.

${ }^{\mathrm{d}}$ Culture collection of B. H. Bluhm, University of Arkansas, Fayetteville, U.S.A. 
The $C$. zeina $C T B 7$ gene region has deletions compared with the corresponding genomic DNA (gDNA) region in $C$. zeae-maydis.

Based on in silico annotation and the lack of in vitro expression, the $C$. zeina CMW25467 CTB7 gene appeared to be defective. Comparison of gDNA sequences between the two GLS pathogens revealed a series of deletions in the $C$. zeina $C T B 7$ region, corresponding to part of exon one and the intron of C. zeae-maydis CTB7 (nucleotides 225 to 678) (Fig. 2). There was high sequence identity $(86 \%)$ for the region corresponding to the first $224 \mathrm{bp}$ of $C$. zeae-maydis exon one as well as for the second $C T B 7$ exon of $C$. zeae-maydis (87\% identity; nucleotides 679 to 1,332 ) (Fig. 2).

The $C$. zeina $C T B 7$ gene region is transcribed during in planta glasshouse trials and exhibits splicing of an intron at a different position from the in silico prediction.

High nucleotide sequence identity between the $C$. zeina $C T B 7$ gene region and the exons of $C$. zeae-maydis CTB7 (Fig. 2 ), together with the in silico prediction of a putative 322 amino acid $C$. zeina CTB7 polypeptide (Table 2), led us to seek
A
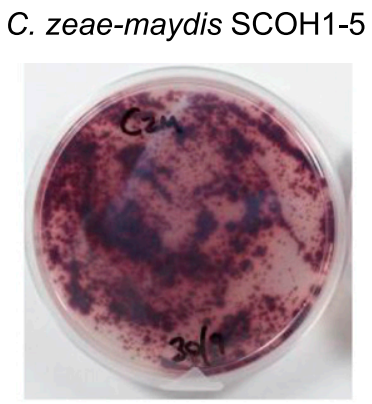

C. zeina CMW25467

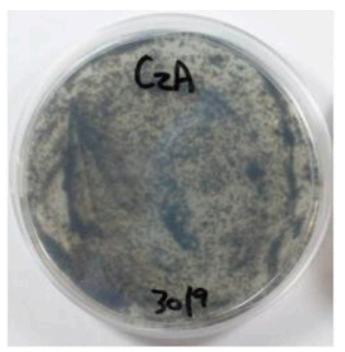

C. zeina OYPA

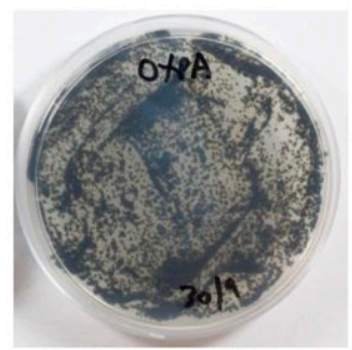

B

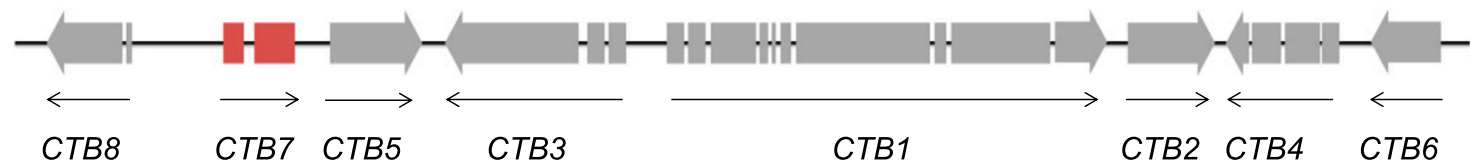

Fig. 1. Cercospora zeina fails to produce cercosporin in vitro, despite carrying a largely intact cercosporin toxin biosynthetic (CTB) gene cluster. A, Cercospora zeae-maydis SCOH1-5 produces cercosporin when cultured on $0.2 \times$ potato dextrose agar (PDA) (visible as the accumulation of a red pigment in the media). Neither the African nor the United States isolates of $C$. zeina, CMW25467 and OYPA, respectively, produce cercosporin when cultured on 0.2× PDA. B, The $C T B$ gene cluster of $C$. zeina CMW25467 is intact except for CTB7. The position, orientation, and structure of the predicted genes are indicated by the arrows. Following automated gene predictions, manual annotations were performed, based on multiple sequence alignments of the encoded amino acid sequences with the CTB amino acid sequences of $C$. nicotianae and C. zeae-maydis.

Table 2. The Cercospora zeina cercosporin toxin biosynthetic (CTB) gene cluster

\begin{tabular}{|c|c|c|c|c|c|c|c|c|}
\hline \multirow[b]{2}{*}{$\begin{array}{l}\text { C. zeina } \\
C T B \text { gene }^{\mathrm{a}}\end{array}$} & \multirow[b]{2}{*}{ Length $(\mathbf{b p})^{\mathbf{b}}$} & \multirow[b]{2}{*}{$\begin{array}{l}\text { Intron } \\
\text { number }\end{array}$} & \multirow[b]{2}{*}{$\begin{array}{l}\text { Amino } \\
\text { acids }\end{array}$} & \multicolumn{2}{|l|}{ NCBI BLASTx $\operatorname{search}^{c}$} & \multicolumn{3}{|c|}{ Pairwise alignment $^{d}$} \\
\hline & & & & $\begin{array}{l}\text { Best BLASTx match } \\
\text { (accession number) }\end{array}$ & E value & Identity (\%) & Similarity (\%) & Gaps (\%) \\
\hline CTB1 & 6,588 & 9 & 2,195 & $\begin{array}{l}\text { Polyketide synthase (Cercospora } \\
\text { nicotianae) (AAT69682.1) }\end{array}$ & 0.0 & 85.0 & 91.2 & 0.9 \\
\hline CTB2 & 1,359 & 0 & 452 & $\begin{array}{l}O \text {-methyltransferase (Cercospora } \\
\text { nicotianae) }(\mathrm{ABK} 64180.1)\end{array}$ & 0.0 & 85.9 & 90.4 & 4.3 \\
\hline CTB3 & 2,619 & 2 & 872 & $\begin{array}{l}\text { Cercosporin toxin biosynthesis protein } \\
\text { (Cercospora nicotianae) (ABC79591.2) }\end{array}$ & 0.0 & 87.5 & 93.1 & 0.2 \\
\hline CTB4 & 1,539 & 3 & 512 & $\begin{array}{l}\text { Major facilitator superfamily transporter } \\
\text { (Cercospora nicotianae) (ABK64181.1) }\end{array}$ & 0.0 & 89.9 & 95.9 & 0.2 \\
\hline CTB5 & 1,386 & 0 & 461 & $\begin{array}{l}\text { Oxidoreductase (Cercospora nicotianae) } \\
\text { (ABK64182.1) }\end{array}$ & 0.0 & 90.9 & 95.9 & 0.6 \\
\hline СТВ6 & 1,065 & 0 & 354 & $\begin{array}{l}\text { Reductase (Cercospora nicotianae) } \\
\quad(\text { ABK64183.1) }\end{array}$ & 0.0 & 86.6 & 94.7 & 0.6 \\
\hline $\begin{array}{l}C T B 7 \text { gene } \\
\text { region }\end{array}$ & 969 & 1 & 322 & $\begin{array}{l}\text { Oxidoreductase (Cercospora nicotianae) } \\
\text { (ABK64184.1) }\end{array}$ & $1 \mathrm{e}-120$ & 51.4 & 55.6 & 36.6 \\
\hline CTB 8 & 1,278 & 1 & 425 & $\begin{array}{l}\text { Zinc finger transcription factor } \\
\text { (Cercospora nicotianae) (ABK64185.1) }\end{array}$ & $8 e-151$ & 68.5 & 77.1 & 7.7 \\
\hline
\end{tabular}

${ }^{a}$ Annotated nucleotide sequence of the C. zeina CMW25467 CTB gene cluster is available on GenBank (accession number KY656140).

b The length of the predicted coding DNA sequence (introns excluded).

c Predicted $C$. zeina $C T B$ gene sequences used as queries in a National Center for Biotechnology Information (NCBI) BLASTx search against the nonredundant protein sequences (nr) database (E value indicated).

d The best BLASTx hits and predicted $C$. zeina CTB amino acid sequences were subjected to a pairwise sequence alignment and the identity, similarity, and gap percentages are indicated.

e In silico annotation of the $C T B 7$ gene region with incorrect intron position, prior to identification of intron position from in planta expression data (discussed later). 
further experimental evidence to annotate the CTB7 gene model. We hypothesized that, although the gene did not appear to be expressed in vitro, it may be expressed in planta.

We conducted a glasshouse inoculation trial of the susceptible maize inbred B73 with C. zeina CMW25467 and extracted RNA at $0,12,19,21$, and 25 days postinoculation (dpi). Typical GLS lesions had formed by 19 dpi and had progressed to coalesced lesions by $25 \mathrm{dpi}$ on all replicate plants. C. zeina fungal load was quantified by quantitative polymerase chain reaction (qPCR) and was shown to increase over the time course, with a significant difference at 21 and 25 dpi compared with the 0 -dpi samples (Supplementary Fig. S1).

RNA from all the time points were pooled and were used for reverse transcription (RT)-PCR analysis with the CTB7exon primer pair (Table 4), which flank the in silico-predicted intron in the $C$. zeina $C T B 7$ gene region (Fig. 2). Sequence analysis revealed the presence of a 112-bp intron with a canonical GT-AG donor-accepter pair as well as a consensus branch site (CTAAC) (Reid et al. 2014; Rep et al. 2006) situated $8 \mathrm{bp}$ from the acceptor (Fig. 3A). Importantly, the donor site of the true intron was 10 nucleotides downstream of the in silico-predicted intron (Figs. 2 and $3 \mathrm{~A}$ ). The intron was $12 \mathrm{bp}$ larger than the predicted intron in the $C$. zeae-maydis $C T B 7$, but the acceptor site was at the same position (Fig. 2).

A second glasshouse trial was carried out and RNA was extracted from three biological replicates of $C$. zeina-infected B73 maize plants, at $32 \mathrm{dpi}$, with typical GLS lesions. All three replicates produced the 122-bp RT-PCR product (Fig. 3B, lanes 4 to 6), confirming expression of the $C$. zeina $C T B 7$ gene and indicating removal of the $C T B 7$ intron. However, there was incomplete splicing of some transcripts, since a 234 -bp product was also observed in each sample, which corresponds to the size of the gDNA product (Fig. 3B, lanes 4 to 6). RT-PCR analysis of the $C$. zeina elongation factor $1 \alpha$ gene, the primers

Table 3. Expression of the Cercospora zeina cercosporin toxin biosynthetic $(C T B)$ genes under in vitro growth conditions and in planta (field)

\begin{tabular}{|c|c|c|c|c|c|c|c|c|c|c|}
\hline \multirow[b]{3}{*}{ Gene } & \multicolumn{10}{|c|}{ Gene expression (counts) ${ }^{a}$} \\
\hline & \multicolumn{7}{|c|}{ In vitro } & \multicolumn{3}{|c|}{ In planta ${ }^{b}$} \\
\hline & V8 & PDA+AP & PDA pH8 & PDA pH3 & Corn agar & $\mathbf{C M}$ & YPD & Replicate 1 & Replicate 2 & Replicate 3 \\
\hline CTB1 & 835 & 1,645 & 1,828 & 639 & 1,834 & 1,930 & 1,104 & 149 & 68 & 76 \\
\hline СТВ2 & 20 & 103 & 45 & 60 & 84 & 84 & 22 & 2 & 1 & 6 \\
\hline СТВ3 & 492 & 884 & 849 & 579 & 1,115 & 1,059 & 1,906 & 73 & 49 & 85 \\
\hline СТB4 & 86 & 135 & 113 & 66 & 128 & 145 & 140 & 35 & 24 & 14 \\
\hline СТВ5 & 318 & 895 & 669 & 288 & 979 & 1,179 & 903 & 61 & 56 & 57 \\
\hline СТВ6 & 41 & 346 & 65 & 117 & 192 & 250 & 225 & 96 & 81 & 93 \\
\hline CTB7 & 0 & 0 & 0 & 0 & 0 & 0 & 0 & 0 & 0 & 0 \\
\hline СТВ8 & 241 & 416 & 410 & 259 & 489 & 453 & 453 & 18 & 21 & 55 \\
\hline $40 S$ & 31,344 & 9,852 & 13,666 & 10,550 & 10,857 & 19,034 & 9,694 & 11,368 & 8,881 & 13,053 \\
\hline$E F 1 \alpha$ & 179,348 & 54,366 & 140,673 & 85,332 & 84,579 & 132,714 & 243,946 & 4,192 & 2,835 & 4,541 \\
\hline
\end{tabular}

a Number of RNA sequence reads which mapped to the gene of interest. $\mathrm{PDA}=$ potato dextrose agar, $\mathrm{AP}=$ ammonium phosphate, $\mathrm{CM}=$ complete medium, and YPD = yeast extract peptone dextrose.

b RNA isolated from field grown B73 maize leaves demonstrating gray leaf spot lesions.

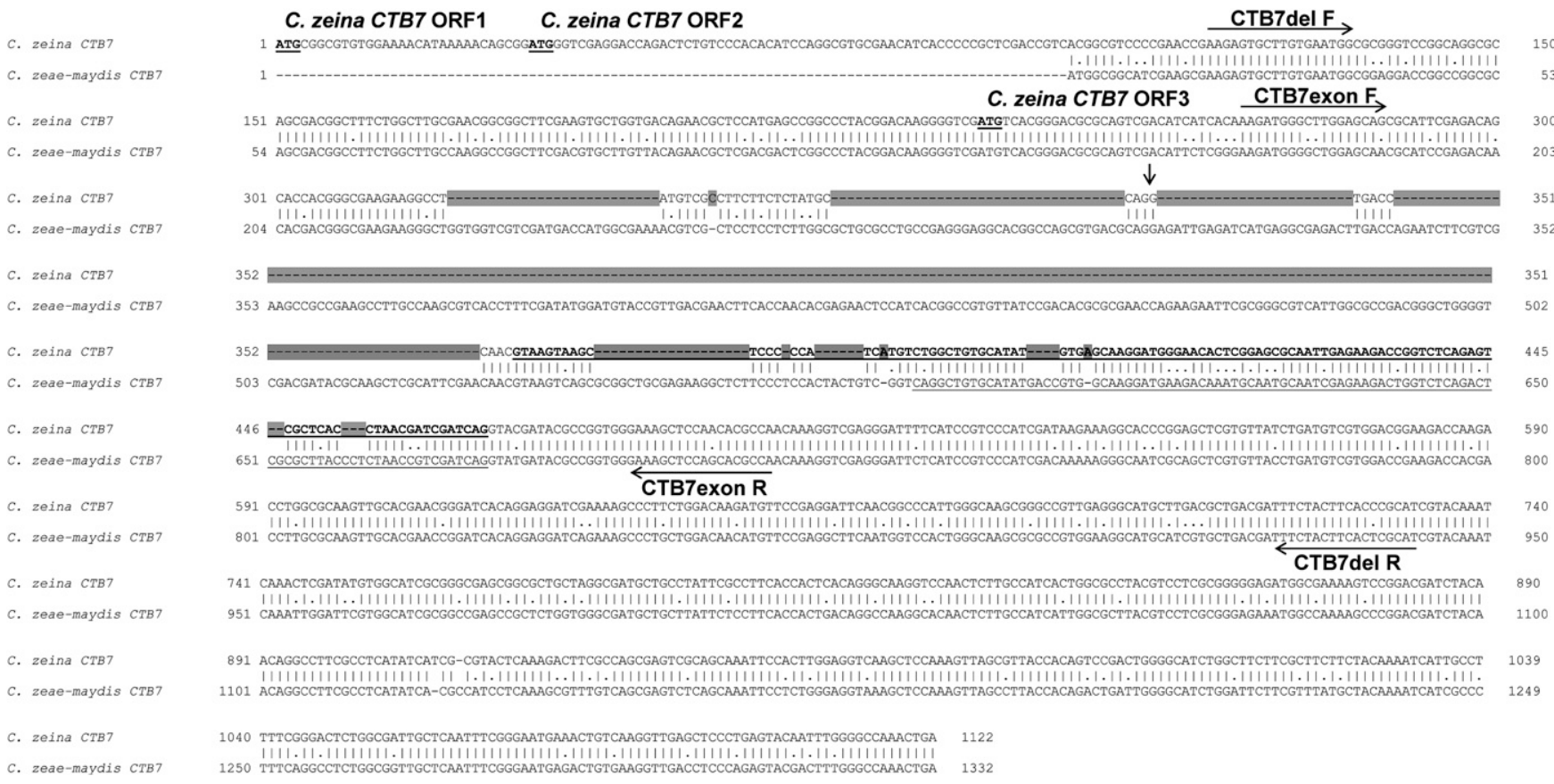

Fig. 2. Pairwise alignment of Cercospora zeina CMW25467 and C. zeae-maydis SCOH1-5 CTB7 genomic DNA nucleotide sequences. The three potential translation start sites for the C. zeina CTB7 gene are underlined and in bold. The positions corresponding to the CTB7del and CTB7exon primer binding sites are indicated by horizontal arrows. Indels present in the $C$. zeina nucleotide sequence are highlighted in gray. The position of the in silico-predicted intron splice site for $C$. zeina CTB7 is indicated by a vertical arrow (used to predict the $322-$ amino acid CTB7 polypeptide). The $C$. zeae-maydis intron sequence is underlined. The C. zeina intron sequence of the transcripts expressed in planta is shown in bold and underlined (as validated by reverse transcriptionpolymerase chain reaction and sequencing using the CTB7exon primer pair). 
of which flank an intron (Table 4), produced only the smaller 99-bp spliced product, indicating that there was no gDNA contamination in the samples (Fig. 3C, lanes 4 to 6).

Additional evidence for expression of $C T B 7$ in the glasshouse trials was obtained by RT-qPCR, using the CTB7 primer pair (Table 4) designed to the $C$. zeina CTB7 region, with high identity to the $\mathrm{C}$-terminal region of $C$. zeae-maydis CTB7. C. zeina $C T B 7$ expression could be quantified at all time points from 0 to $25 \mathrm{dpi}$, although expression was low and there were no significant differences between the time points (Fig. 4C). Similarly, three other $C$. zeina $C T B$ genes (CTB1, CTB2, and $C T B 8$ ) were analyzed as controls and showed a trend of increased expression over time, although there were no significant differences to the 0-dpi samples (Fig. 4A, B, and D). Amplification of specific products for the $C T B$ and normalization control genes was verified by sequencing the RT-qPCR products and melt-curve analysis (Supplementary Fig. S2). This result for $C T B 7$ was corroborated by RT-PCR analysis of the B73-GLS samples from the second glasshouse trial with the same primers, to show the expected product of $98 \mathrm{bp}$ in all three replicates (Supplementary Fig. S3).

RNA-seq analysis of a field infection of maize B73 with natural isolates of $C$. zeina at a GLS hotspot in South Africa (Greytown, KwaZulu-Natal) revealed the in planta expression of all $C T B$ genes except $C T B 7$ in all three replicate plants (Table 3). The field leaf samples were characterized by individual GLS lesions covering $8 \%$ of the leaf surface area, on average, and therefore, had not yet coalesced (Christie et al. 2017), in contrast to the glasshouse samples that were inoculated at high conidial density, resulting in lesions that were coalesced by 21 to $25 \mathrm{dpi}$.
We suggest that the field samples were at an earlier stage of GLS disease development or the isolates were less aggressive, thus, CTB7 expression was below the detection threshold. Additionally, for these samples, RT-qPCR (glasshouse samples) may have been more sensitive than RNA-seq (field samples), considering the amount of fungal RNA compared with maize RNA in the field samples with lower fungal load.

\section{The $C$. zeina $C T B 7$ gene region does not encode a full-length oxidoreductase protein based on the intron position.}

Identification of the intron position in the C. zeina CTB7 gene region from the in planta transcripts showed that the in silico-predicted intron position was incorrect, and thus, the putative 322-amino acid CTB7 polypeptide shown in Table 2 was invalid. The correct intron position was used to predict the open reading frames (ORFs) across the gene. None of the three possible ORFs encode a complete CTB7 protein corresponding to the full-length CTB7 from C. zeae-maydis (Fig. 5A). ORF 1 encodes a 151-amino acid polypeptide with no similarity to the CTB7 orthologs (Fig. 5A). ORF 2 encodes a 105-amino acid polypeptide that is highly similar to the $\mathrm{N}$-terminus of the C. nicotianae $(62.9 \%$ identity) and C. zeae-maydis $(59.0 \%$ identity) $C T B 7$ orthologs but ends in a stop codon before the intron (Fig. 5B). ORF 3 encodes a 257-amino acid protein - the first 39 amino acids before the intron show no similarity to the $C$. nicotianae and $C$. zeae-maydis CTB7 orthologs. The remaining 218 amino acids of ORF 3 are highly similar to the C-terminal half of the $C$. nicotianae $(78.9 \%$ identity) and C. zeae-maydis $(92.6 \%$ identity) $C T B 7$ orthologs and

Table 4. Primer sequences used in this study

\begin{tabular}{|c|c|c|c|}
\hline Primer name & Sequence $\left(5^{\prime}-3^{\prime}\right)$ & Gene target & Amplicon size (bp) \\
\hline \multicolumn{4}{|c|}{$C T B 7$ gDNA structure analysis } \\
\hline CTB7del F & AAGAGTGCTTGTGAATGG & Cercospora CTB7 & 618 (Cercospora zeina) \\
\hline CTB7del R & GATGCGGGTGAAGTAGAAA & Cercospora CTB7 & 925 (C. zeae-maydis) \\
\hline \multicolumn{4}{|c|}{ Reverse transcription-polymerase chain reaction (RT-PCR) primers } \\
\hline CTB7exon $\mathrm{F}$ & AAGATGGGCTTGGAGCAG & C. zeina $C T B 7$ & 234 (gDNA) \\
\hline CTB7exon $\mathrm{R}$ & TGGCGTGTTGGAGCTTTC & C. zeina $C T B 7$ & 122 (cDNA) \\
\hline CzmCTB7 F & GATTGAGATCATGAGGCGAGAC & C. zeae-maydis CTB7 & 100 \\
\hline CzmCTB7 R & AAGTTCGTCAACGGTACATCC & C. zeae-maydis CTB7 & 100 \\
\hline $\mathrm{EF} 1 \alpha \mathrm{F}$ & GTGCTCGACAAGCTGAA & C. zeina elongation factor $1 \alpha$ & 154 (gDNA) \\
\hline $\mathrm{EF} 1 \alpha \mathrm{R}$ & GTCGATGACGGTGACATAG & C. zeina elongation factor $1 \alpha$ & 99 (cDNA) \\
\hline \multicolumn{4}{|c|}{ Quantitative RT-PCR primers } \\
\hline CTB1 F & GCCTCCAGATGGCATTAT & C. zeina $C T B 1$ & 96 \\
\hline CTB1 R & CGTAGAGTGCAGCGTATT & C. zeina $C T B 1$ & 96 \\
\hline CTB2 F & CCTAGACCAGAAAGGACTTC & C. zeina $C T B 2$ & 97 \\
\hline CTB2 R & GCTTCTCGCATCGTAGTA & C. zeina $C T B 2$ & 97 \\
\hline CTB7 F & GCCTTCGCCTCATATCAT & C. zeina $C T B 7$ & 98 \\
\hline CTB7 R & GACTGTGGTAACGCTAACT & C. zeina $C T B 7$ & 98 \\
\hline CTB8 F & TGTCATCGTGTCAGTCATC & C. zeina $C T B 8$ & 95 \\
\hline CTB8 R & AATCTTGGCCTCGACATC & C. zeina $C T B 8$ & 95 \\
\hline $40 \mathrm{~S} \mathrm{~F}$ & GGTCCTCAAGGTCATTCTC & C. zeina $40 S$ ribosomal protein & 102 \\
\hline $40 \mathrm{~S} \mathrm{R}$ & TTGACACCCTTTCCAGTC & C. zeina $40 S$ ribosomal protein & 102 \\
\hline Cyt III F & GAGCTCTTTATGGTGCTCTA & C. zeina cytochrome c oxidase III & 108 \\
\hline Cyt III R & CGTAGGCTCCATCTGATAAA & C. zeina cytochrome c oxidase III & 108 \\
\hline \multicolumn{4}{|c|}{ Plasmid construction (restriction enzyme sites appear in bold) ${ }^{\mathrm{a}}$} \\
\hline MCS HYG_XhoI F & $\begin{array}{l}\text { GGGCTCGAGACTGGTACCGCGG } \\
\text { GCCCTAGGCCTTACGTAGGAGCTCCACC } \\
\text { GCGGTGGCG }\end{array}$ & Hygromycin-resistance cassette & 2,008 \\
\hline HYG_BstEII R & $\begin{array}{l}\text { GGCGGTGACCGGGGA } \\
\text { TCCACTAGTTCTAGAGCGGCC }\end{array}$ & Hygromycin-resistance cassette & 2,008 \\
\hline GFP_BamHI F & GGCGGATCCGGAGAGCTTATACCGAGCTCCC & $\begin{array}{l}\text { Green fluorescent protein (GFP) } \\
\text { expression cassette }\end{array}$ & 1,814 \\
\hline MCS GFP_BstEII R & $\begin{array}{l}\text { GGCGGTGACCTCAAGCTT } \\
\text { GCTTAATTAATCCCGGGTTACTT } \\
\text { GTACAGCTCGTCCATGCC }\end{array}$ & GFP expression cassette & 1,814 \\
\hline XbaI-CTB7-F & ATATATCTAGAGGTACAGTAGCTCACCACGT & C. zeae-maydis CTB7 & 3,409 \\
\hline BamHI-CTB7-RC & TATATGGATCCTGATTGAGAGTAAGCCGC & C. zeae-maydis CTB7 & 3,409 \\
\hline
\end{tabular}

${ }^{\mathrm{a}} \mathrm{MCS}=$ multiple cloning site, GFP $=$ green fluorescent protein . 
include the predicted amidation and FMN/FAD-binding motifs (Fig. 5B). However, the C. zeina ORF 3 lacks approximately 220 amino acids at the $N$-terminus (containing a second FMN/FAD-binding motif) that are present in the CTB7 proteins from the other Cercospora species (Fig. 5B). Currently, it is not known if any of these potential CTB7 ORFs are translated into active proteins in C. zeina. C. zeae-maydis CTB7 has a 40amino acid deletion compared with the $C$. nicotianae CTB7 (Fig. 5B) but, in contrast to C. zeina, C. zeae-maydis still maintains the ability to produce cercosporin (Fig. 1A).

The deletion in the gDNA of the $C$. zeina $C T B 7$ gene region compared with $C$. zeae-maydis is conserved in $C$. zeina isolates from Africa and the United States.

The sequence conservation between the $C$. zeina CTB7 gene region and the nucleotides corresponding to the $\mathrm{N}$ - and $\mathrm{C}$-termini of $C$. zeae-maydis CTB7 was exploited to design a diagnostic PCR assay. The CTB7del primer pair, which flanks the region of deletions and the intron in C. zeina, produced 618- and 925-bp amplicons from gDNA of $C$. zeina and C. zeae-maydis, respectively (Fig. 6A and B). A suite of C. zeina isolates from both Africa
(Uganda and Zambia) and the United States (Pennsylvania, Ohio, New York) were screened and all were found to carry the smaller CTB7 amplicon predicted to occur in C. zeina CMW25467 (Fig. 6C). The species identity of these isolates was confirmed to be $C$. zeina, using a histone gene diagnostic PCR (Supplementary Fig. S4) (Crous et al. 2006). Sequence analysis of the $C T B 7$ gene region from a United States isolate (OYPA, USPA-4) showed it to be identical to the Zambian isolate CMW25467 and a selection of seven additional isolates from Zambia, Kenya, and South Africa (Supplementary File $\mathrm{S} 2$ ). There was a single nucleotide polymorphism in an isolate from Uganda.

\section{Cercosporin production}

in $C$. zeina $\mathrm{CzmCTB7}$ transformants.

$C$. zeina was complemented with the full-length $C$. zeae-maydis $C T B 7$ gene using A. tumefaciens-mediated transformation (Supplementary Fig. S5). The presence of the C. zeae-maydis CTB7 gene was confirmed in four transformants, using the $C T B 7$ diagnostic PCR, which showed amplicons for both copies of the CTB7 gene (618 bp from C. zeina and the 925 bp from

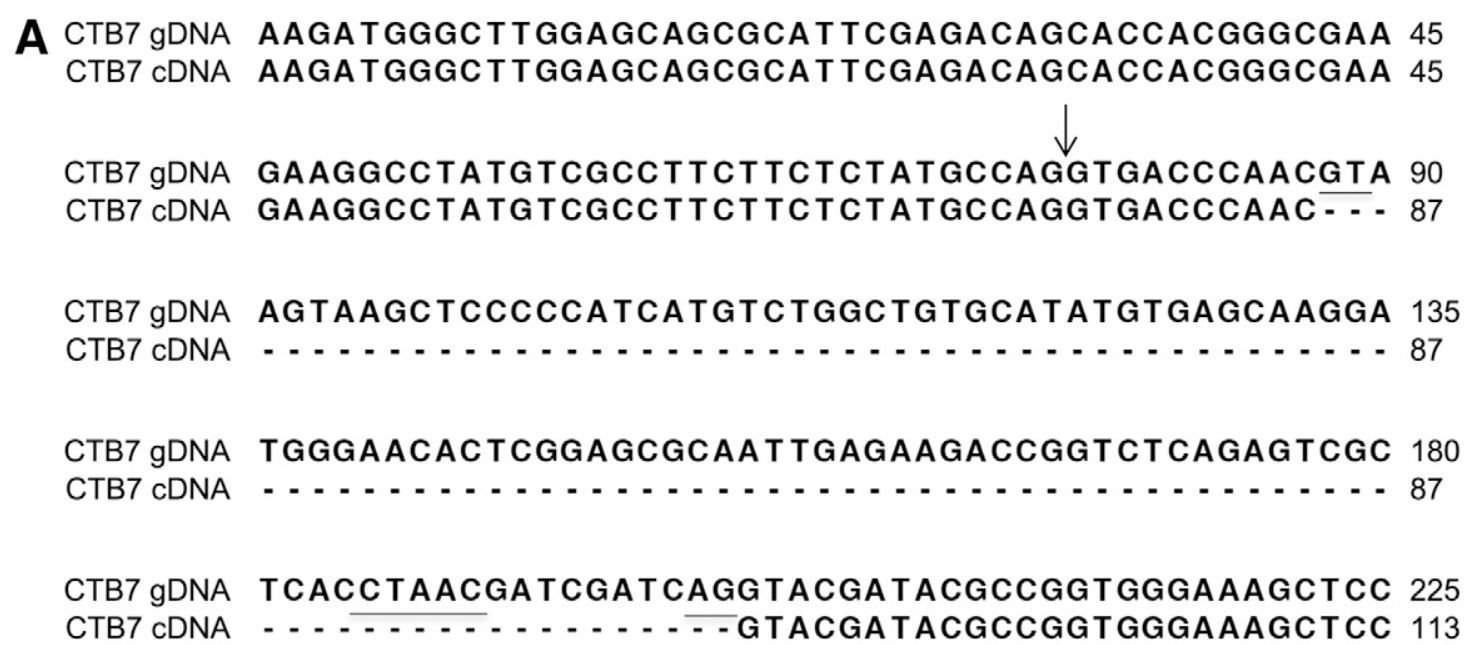

CTB7 gDNA AACACGCCA 234

CTB7 CDNA AACACGCCA 122

B

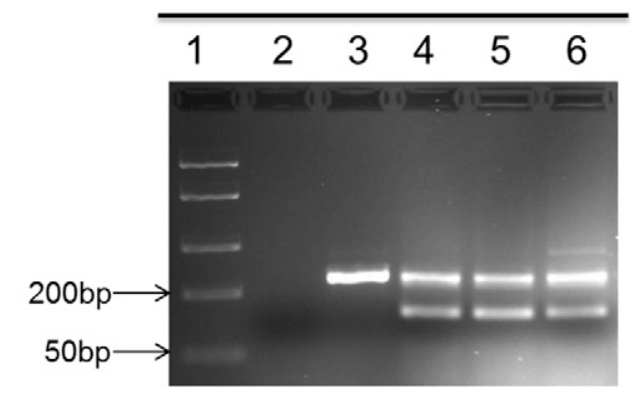

C

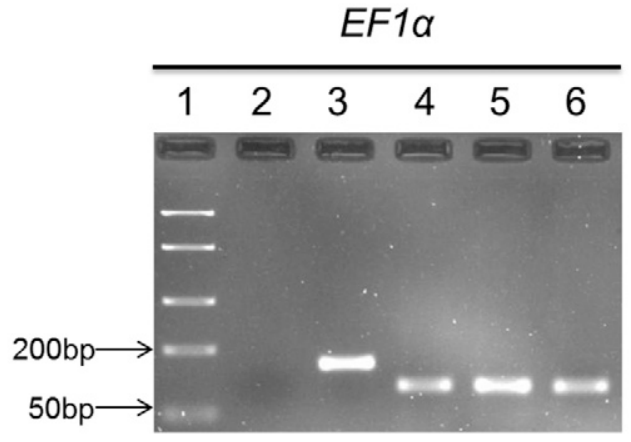

Fig. 3. The Cercospora zeina CTB7 gene region is expressed and an intron is spliced in planta. A, Alignment of $C$. zeina CTB7 gDNA and cDNA sequences amplified with CTB7exon primer pair indicates CTB7 expression in C. zeina-inoculated B73 maize during glasshouse trial 1 and removal of the 112-bp intron. The consensus GT-AG donor-acceptor and CTAAC branch sites are underlined in the cDNA. The position of the incorrect in silico-predicted intron donor site (used to predict the incorrect 322-amino acid CTB7 polypeptide) is indicated by a vertical arrow and occurs 10 nucleotides upstream of the correct site in C. zeina CTB7. B, Confirmation of C. zeina CTB7 expression and intron splicing in C. zeina-inoculated B73 maize during glasshouse trial 2. The CTB7 reverse transcription-polymerase chain reaction (RT-PCR) (CTB7exon primers) generated two products in each inoculated maize replicate (lanes 4 to 6), one corresponding to the expected cDNA amplicon with intron removed (122 bp) and a larger amplicon (234 bp) indicating the presence of nonspliced CTB7 transcripts. Nontemplate/water controls were included in lane 2 and a $C$. zeina gDNA positive control in lane 3 . RT-PCR products were separated on a $2 \%$ agarose gel stained with ethidium bromide. A size standard (FastRuler low range DNA ladder [ThermoFisher Scientific]) is shown in lane 1. C, The EFl $\alpha$ RT-PCR (EF1 $\alpha$ primers) demonstrated no gDNA contamination in the three replicates (lanes 4 to 6). Electrophoresis conditions and equivalent controls were as described for B. 
C. zeae-maydis) (Fig. 7A). RT-PCR analysis showed that these transformants also expressed the C. zeae-maydis CTB7 gene when cultured on 0.2× PDA under constant light (Fig. 7B). Furthermore, transformant 3 was found to accumulate a red pigment comparable to an isolate of C. kikuchii (Fig. 8), a species known to produce cercosporin (Kuyama and Tamura 1957). As expected, none of the isolates produced the red pigment when grown on $0.2 \times$ PDA plus $10 \mathrm{mM}$ ammonium phosphate (Fig. 8), conditions known to suppress cercosporin production (You et al. 2008). Both the $\mathrm{KOH}$ assay and thinlayer chromatography (TLC) indicated cercosporin production in transformant 3 (Fig. 9). These results were confirmed by ultra performance liquid chromatography-quadrupole-time-offlight mass spectrometry (UPLC-QTOF-MS) (Fig. 10).

The high resolution mass spectra (HRMS) for the cercosporin standard and the extract from transformant 3 are shown in Figure 10. Both pure cercosporin and transformant 3 exhibited a peak at a retention time of $6.30 \mathrm{~min}$ on the UPLC profile (Fig. $10 \mathrm{~A}$ and $\mathrm{B})$. The HRMS-electrospray ionization/atmospheric pressure chemical ionization-TOF $(\mathrm{m} / \mathrm{z})\left(\mathrm{MH}^{+}\right)$previously calculated for cercosporin $\left(\mathrm{C}_{29} \mathrm{H}_{27} \mathrm{O}_{10}\right)$ was 535.1604 (Newman and Townsend 2016). We observed an accurate mass of 535.1606 for the cercosporin standard and 535.1605 for transformant 3 (Fig. 10C and D). The values of HRMS main fragments as shown on the MS/MS profiles for cercosporin and transformant 3 (Fig. 10E and F) and C. kikuchii (Supplementary Fig. S6C) are provided in Supplementary Table S1. These data are in accordance with that previously published for cercosporin (Yamazaki and Ogawa 1972). Cercosporin was absent from the UPLC profile of the C. zeina wild-type extract.
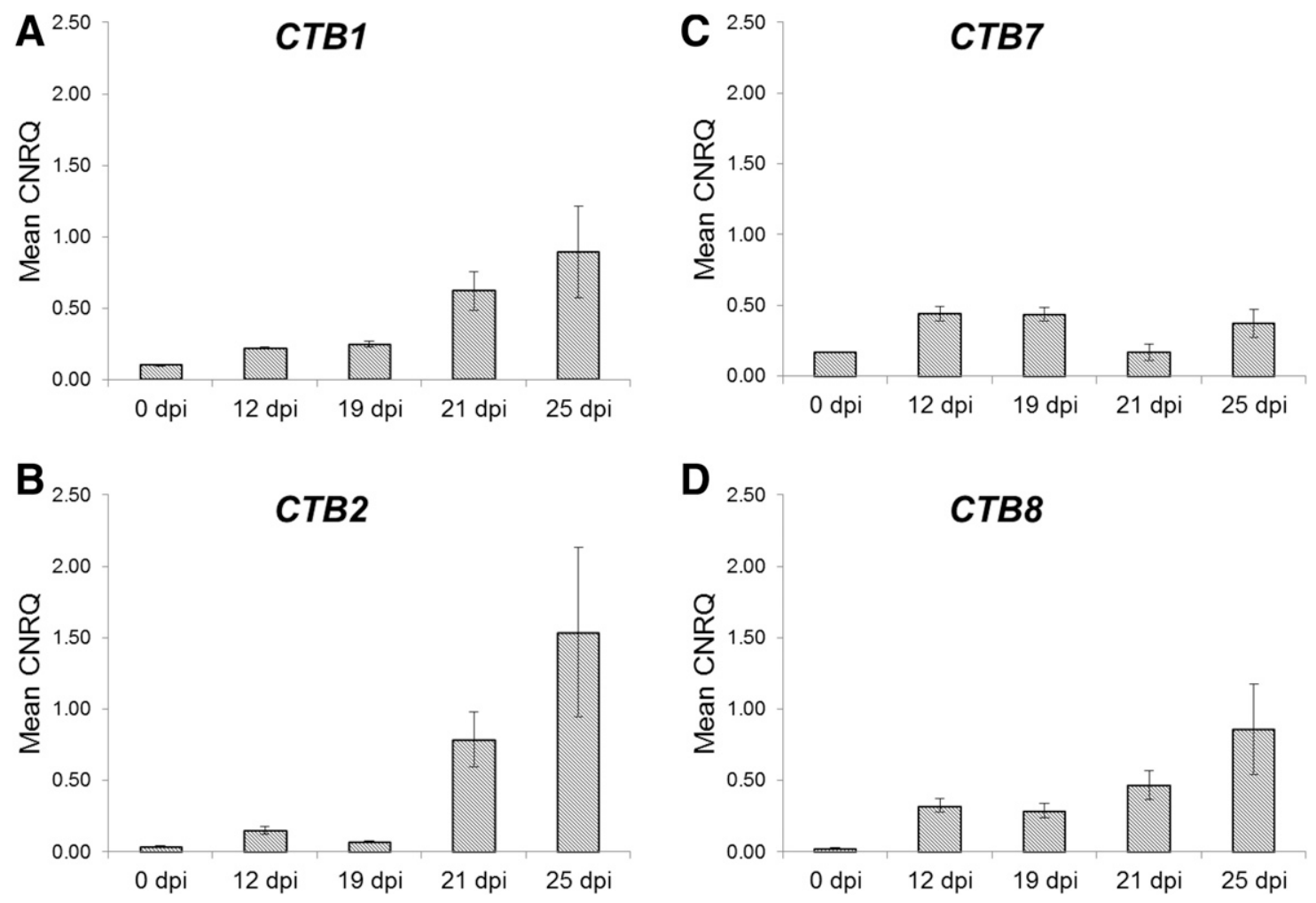

Fig. 4. Cercospora zeina CTB7 and three other $C T B$ genes $(C T B 1, C T B 2$, and $C T B 8)$ were shown to be expressed in B73 maize inoculated with $C$. zeina CMW25467 during glasshouse trial 1 . Reverse transcription quantitative polymerase chain reaction was carried out on RNA extracted from maize at different time points after inoculation and was used to calculate mean calibrated normalized relative quantity (CNRQ) values for A, CTB1, B, CTB2, C, CTB7, and D, $C T B 8$. The relative expression values were normalized against the stably expressed reference genes $40 S$ and $C y t I I I$. Standard error bars are included on the graphs. Statistical analysis was done using one-way analysis of variance with a Tukey's multiple comparison test. None of the $C T B$ genes studied showed a statistically significant $(\alpha=0.05)$ difference in expression compared with 0 days postinoculation (dpi). Only two biological replicates were included in the analysis for 0 dpi. 
evidence that 12 of 77 pseudogenes were expressed (Lafontaine and Dujon 2010). C. zeina CTB7 was expressed at low levels in planta (Fig. 4C), although not all transcripts were spliced (Fig. 3B). All the other intact $C T B$ genes were expressed both in vitro and in planta (Table 3 ).

The predicted ORFs for $C$. zeina $C T B 7$ all lack some of the functional groups described in the $C$. nicotianae ortholog and are, thus, unlikely to have full CTB7 activity (Fig. 5). Proteomic analysis of GLS lesions may reveal which, if any, of the C. zeina CTB7 ORFs are translated; however, based on the observed low expression level of $C T B 7$ and expected relative high abundance of maize proteins, its presence may be below the detection limit.

If $C T B 7$ represented a nonfunctional gene undergoing pseudogenization, we would expect to observe the accumulation of mutations among different isolates of $C$. zeina. However, sequencing of the CTB7 diagnostic PCR products from the United States isolate OYPA and eight geographically and chronologically separated African $C$. zeina isolates demonstrated remarkable sequence identity, with only one nucleotide difference in a Ugandan isolate. An explanation for this could be a recent geographical separation between $C$. zeina isolates, although this conclusion would require a comprehensive population genetics study.
The accumulated evidence that $C$. zeina $C T B 7$ may be a pseudogene led us to hypothesize that this may explain the lack of cercosporin production in vitro. In a recent study, the metabolite profile of a $C$. nicotianae ctb7 knockout demonstrated a lack of cercosporin and, furthermore, yielded no major compound (Newman and Townsend 2016), similar to what we observed for the wildtype C. zeina UPLC profile. Cercospora nicotianae CTB7, a flavin-dependent oxidoreductase, is, thus, essential for cercosporin production, and it has been proposed to be involved in the formation of the dioxepine ring following the dimerization of the two naphthalene moieties (Newman and Townsend 2016).

Considering the importance of CTB7 in other Cercospora species and to test our hypothesis that CTB7 is the bottleneck in cercosporin production in $C$. zeina, we set out to complement it with a functional CTB7 from the cercosporin-producing species C. zeae-maydis (Bluhm et al. 2008). A. tumefaciensmediated transformation has recently been applied in gene knockout and complementation studies in several Dothideomycetes species, including the northern corn leaf blight pathogen Setosphaeria turcica (Xue et al. 2013), the tomato pathogen Pyrenochaeta lycopersici (Aragona and Valente 2015), as well as C. zeae-maydis ( $\mathrm{Lu}$ et al. 2017), and thus, it was decided to utilize this approach to complement the defective CTB7 gene in $C$. zeina. We successfully generated four transformants that

A

CTB7 ORF 1

Exon 1 (frame 1) Exon 2 (frame 2)

CTB7 ORF 2

Exon 1 (frame 2)

CTB7 ORF 3

Exon 1 (frame 3) $\quad-$ Exon 2 (frame 1)

B

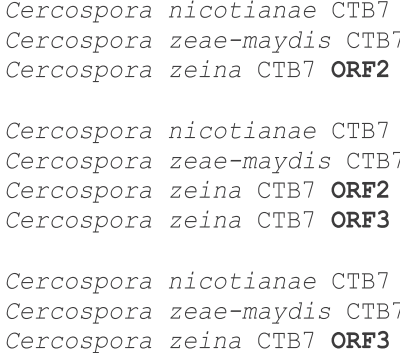

FMN/FAD-binding site

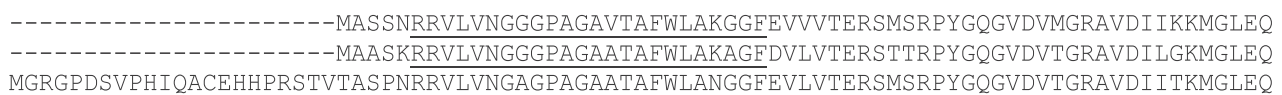

RIRDSTTGEAGLTVVDDQGEDVAPPLGTAPIEGGTASVTQEIEIMRRDLTKIFVDAAEALPNVTFRYGCTVDEVQQHEKSITAVL RIRDNTTGEEGLVVVDDHGENVAPPLGAAPAEGGTASVTQEIEIMRRDLTRIFVEAAEALPSVTFRYGCTVDELHQHENS ITAVL RIRDSTTGEEGLCRLLLYAR*

MSRD-------AQSTSSQRWAWSSAFETAPRAKKAYVAFF

SDTGDPEDFTAI IGADGLGSAIRKLTFDPEINRRSVSPTNTYVAFFS I PGDPKYVSSAARRLSPAPSLCPRSELCDSEGGHDANA

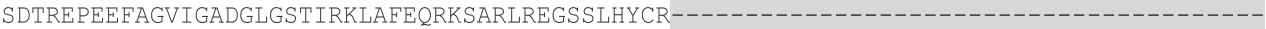
SMPGDPT-

Amidation site

YDTPVGKLQHANKGRGILVRPIDKKGTQRSCYLMSQSDSQELAQVARTGSQEDQKALLDNRFREFTGPLGKRAVEGMHSADDFYF YDTPVGKLQHANKGRGILIRPIDKKGNRS SCYLMSWTEDHDLAQVARTGSQEDQKALLDNMFRGFNGPLGKRAVEGMHRADDFYF YDTPVGKLOHANKGRGIFIRPIDKKGTRSSCYLMSWTEDODLAQVARTGSOEDRKALLDKMFRGFNGPLGKRAVEGMLDADDFYF

\section{FMN/FAD-binding site}

TRIVQIKLDSWHSGRAALVGDAGYSPSPLTGQGTTLAI IGAYVLAGEMAKSPDDLERAFTSYYDILNKFVSESQEIPFGGQAPKI TRIVQIKLDSWHRGRAALVGDAAYSPSPLTGQGTTLAIIGAYVLAGEMAKS PDDLQQAFASYHAILKAFVSESQQIPLGGKAPKI TRIVQIKLDMWHRGRAALLGDAAYSPSPLTGQGPTLAITGAYVLAGEMAKS PDDLQQAFASYHRVLKDFASESQQI PLGGQAPKI

ILPQSDWGIWLLRTFYKIISWTGIWRLLNFGNETVKIE-PEYDFGGLD*
ALPQTDWGIWILRLCYKIIALSGLWRLLNFGNETVKVDLPEYDFGPN-*

ALPQTDWGIWILRLCYKIIALSGLWRLLNFGNETVKVDLPEYDFGPN-*
ALPQSDWGIWLLRFFYKIIAFSGLWRLLNFGNETVKVELPEYNLGPN-*

Fig. 5. The Cercospora zeina CTB7 gene region encodes three potential open reading frames (ORFs), based on the intron position, two of which show similarity to parts of $C T B 7$ in other Cercospora spp. A, C. zeina CTB7 gene region ORF1 encodes a 151-amino acid polypeptide with no sequence similarity to CTB7 orthologs. ORF2 encodes a 105-amino acid polypeptide and shows high similarity to the N-termini of the $C$. nicotianae and $C$. zeae-maydis CTB7 orthologs. ORF3 encodes a 257-amino acid polypeptide, with the last 218 amino acids showing high similarity to the C-terminal region of the $C$. nicotianae and $C$. zeaemaydis CTB7 orthologs. B, Alignment of the $C$. nicotianae CTB7, . zeae-maydis CTB7, and potential $C$. zeina ORF2 and ORF3 CTB7 polypeptides. The intron position is indicated by the vertical black line, with the protein motifs described for $C$. nicotianae CTB7 underlined. The gray highlighted region represents a deletion present in C. zeae-maydis CTB7 compared with the C. nicotianae CTB7. 
were shown to carry both copies of the $C T B 7$ gene (Fig. 7A) and could confirm cercosporin production in one of the transformants (Figs. 8 to 10). The production of cercosporin by the $C$. zeina $C z m C T B 7$ transformant strongly suggests that the $C$. zeina $C T B 7$ gene represents a bottleneck in the biosynthesis pathway.

Chemical assays routinely used to study cercosporin production in vitro are largely dependent on the characteristic red color of the cercosporin molecule that is linked to its highly conjugated structure (Kuyama and Tamura 1957; Yamazaki and Ogawa 1972). Our own analyses demonstrated a lack of red metabolite accumulation in the wild-type $C$. zeina but confirmed cercosporin production in the $C$. zeina $C z m C T B 7$ transformant with the $\mathrm{KOH}$ assay, TLC, and UPLC-QTOF-MS (Figs. 8 to 10 ).
C. zeina is a successful pathogen of maize causing GLS (Meisel et al. 2009; Muller et al. 2016; Wang et al. 1998), despite deletions in the $C T B 7$ gene observed in a range of diverse isolates in this study (Fig. 6). CTB7 has been shown to be important for pathogenicity in at least $C$. nicotianae, since $c t b 7$ knockout mutants show reduced pathogenicity and lack of cercosporin production (Chen et al. 2007a). Mutant studies in several Cercospora spp. have shown a congruence between lack of cercosporin production and reduced pathogenicity (Chen et al. 2007a and b; Choquer et al. 2005, 2007; Dekkers et al. 2007; Shim and Dunkle 2003; Staerkel et al. 2013).

The current study has focused on understanding the lack of cercosporin production in vitro by $C$. zeina, and thus, future work will focus on the role of the CTB pathway, if any, in the pathogenicity of this fungus. However, one hypothesis for the

\section{A}

\section{Cercospora zeae-maydis CTB7}

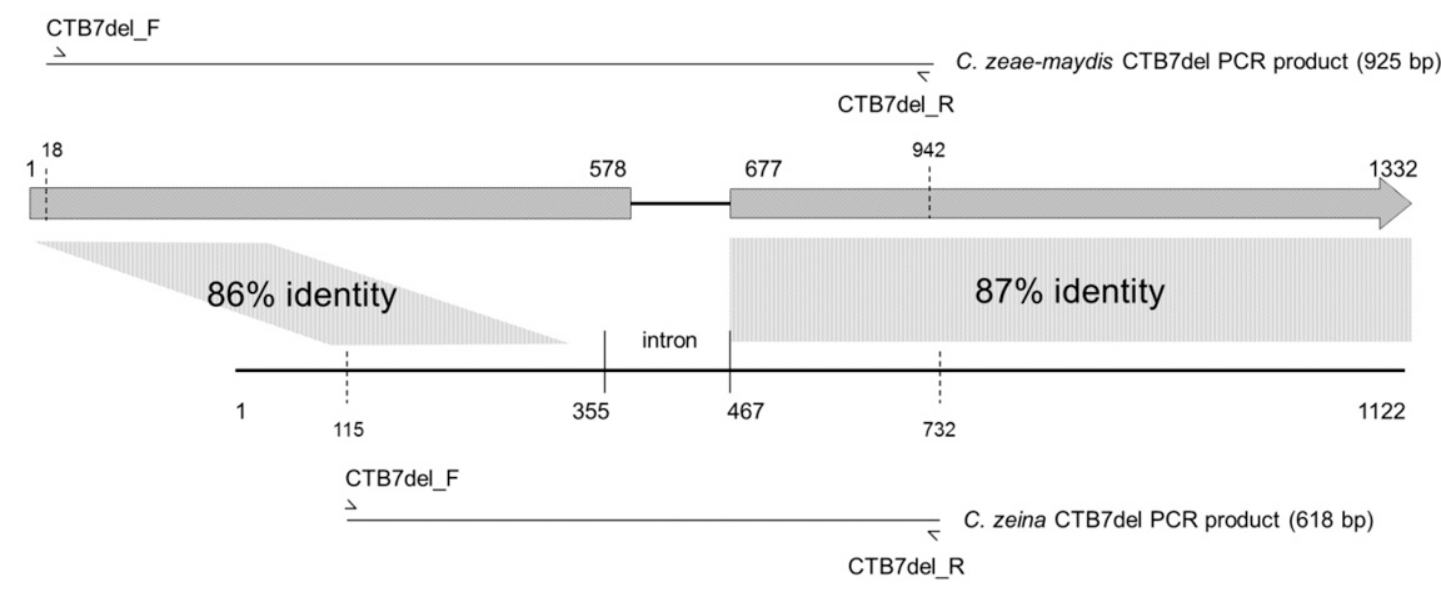

Cercospora zeina CTB7 gene region
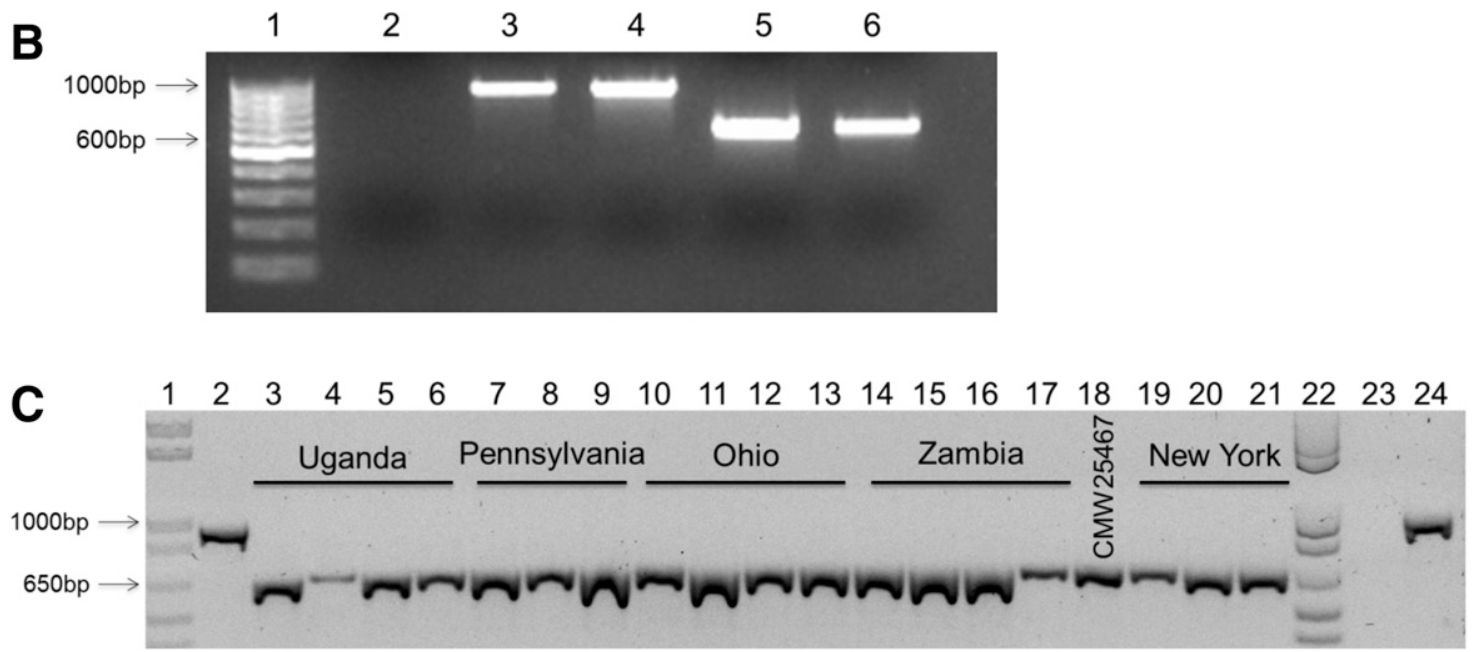

Fig. 6. Screening of Cercospora zeina isolates for the presence of $C T B 7$ genomic DNA deletions. A, Predicted $C T B 7$ gene structures for $C$. zeina and $C$. zeaemaydis, with the position of the CTB7del_F and CTB7del_R primer indicated. The C. zeae-maydis CTB7 gene is indicated with a gray rectangle (exon 1) and a gray arrow (exon 2). The numbers indicate base pair positions from the first nucleotide of the ATG's of the $C$. zeae-maydis $C T B 7$ and the $C$. zeina ORF1. The C. zeina in planta intron is indicated (nucleotides 355 to 467). Regions of greater than $85 \%$ nucleotide identity are shaded. B, Polymerase chain reaction (PCR) amplification from $C$. zeina and $C$. zeae-maydis isolates with CTB7del_F and CTB7del_R primers. PCR products were separated on a 1.5\% agarose gel stained with ethidium bromide. A size standard (GeneRuler 100-bp DNA ladder [ThermoFisher Scientific]) is shown in lane 1. A nontemplate/water control was included in lane 2. C. zeae-maydis (CBS 117757 in lane 3 and CBS 115561 in lane 4) demonstrate the larger 925-bp amplicon, while the C. zeina isolates (CMW25467 in lane 5 and isolate 2011.GT30 in lane 6) yielded a 618-bp amplicon. C, PCR amplification with the same primers was performed on several C. zeina isolates from Africa and the United States. PCR products were separated on a 1\% agarose gel stained with Gel Red. A size standard (1-kb Plus DNA ladder) is shown in lanes 1 and 22. A nontemplate/water control was included in lane 23. C. zeae-maydis SCOH1-5 (lanes 2 and 24) demonstrate the larger 925bp amplicon, while the $C$. zeina isolates (lanes 3 to 21 ) yielded a 618-bp amplicon. 
success of C. zeina despite a nonfunctional CTB7 is that an alternative metabolite is being produced in planta, which maintains a similar function to cercosporin but is not readily detectable visually in vitro.

An alternative hypothesis is that a paralog of C. zeina CTB7 is capable of replacing the function of CTB7, leading to cercosporin production in planta. However, BLAST searches of the $C$. zeina genome with its $C T B 7$ gene region failed to reveal a paralog (data not shown), although this does not preclude the possibility of a dissimilar gene encoding a protein with the same function.

Finally, the use of membrane transporter genes associated with cercosporin autoresistance have been highlighted as candidates for engineering resistance to Cercospora species that have been demonstrated to produce cercosporin during host plant infection (Beseli et al. 2015). The generation of maize lines carrying one or more of these transporter genes in order to combat GLS in regions where C. zeina is predominant may, however, not be advisable if $C$. zeina isolates are incapable of producing cercosporin.

\section{MATERIALS AND METHODS}

All chemicals were purchased from Merck SA, unless otherwise stated.

\section{Biological material and fungal growth conditions.}

CMW25467, the wild-type isolate of Cercospora zeina, was cultured on V8 agar medium at $25^{\circ} \mathrm{C}$ in constant darkness to promote conidiation (Meisel et al. 2009). Conidiating cultures were maintained by subculturing on V8 agar. A South African isolate of $C$. kikuchii was isolated from soybean (Table 1). A
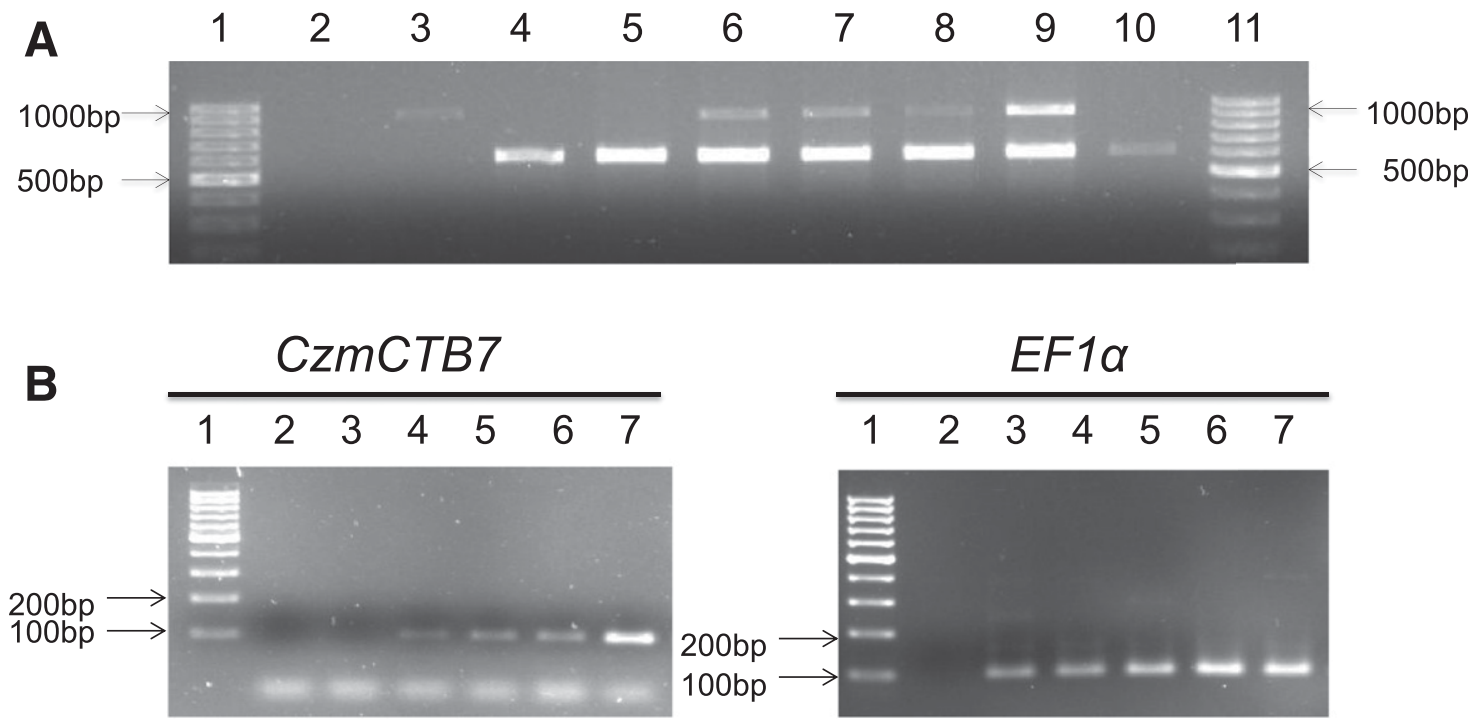

Fig. 7. Cercospora zeina transformants positive for the presence and expression of the $C$. zeae-maydis CTB7 gene. A, Transformants carrying both Cercospora species $C T B 7$ gene copies were detected by polymerase chain reaction (PCR) amplification with the CTB7del primers. PCR products were separated on a $1 \%$ agarose gel stained with ethidium bromide (EtBr). A size standard (GeneRuler 100-bp DNA ladder [ThermoFisher Scientific]) is shown in lanes 1 and 11. A nontemplate/water control was included in lane 2. Positive controls for both C. zeae-maydis (925-bp amplicon, lane 3) and C. zeina (618-bp amplicon, lane 4) were included. Four of the transformants were shown to carry both copies of the $C T B 7$ gene (lanes 6 to 9), while two were shown to only carry the smaller C. zeina CTB7 gene copy (lanes 5 and 10). B, Reverse transcription (RT)-PCR analysis of the transformants grown on $0.2 \times$ potato dextrose agar in constant light to determine expression of the C. zeae-maydis CTB7 gene (CzmCTB7 primers). RT-PCR products were separated on 2\% agarose gels stained with EtBr. A size standard (GeneRuler 100-bp DNA ladder) is shown in lane 1 and a nontemplate/water control is included in lane 2. Lane 3 contained cDNA from C. zeina CMW25467, with lanes 4 to 7 containing cDNA from transformants 2 to 5, respectively. The CzmCTB7 100-bp RT-PCR product was detected in all four of the transformants. The reference gene $E F l \alpha$ was also included to assess the presence of gDNA contamination.

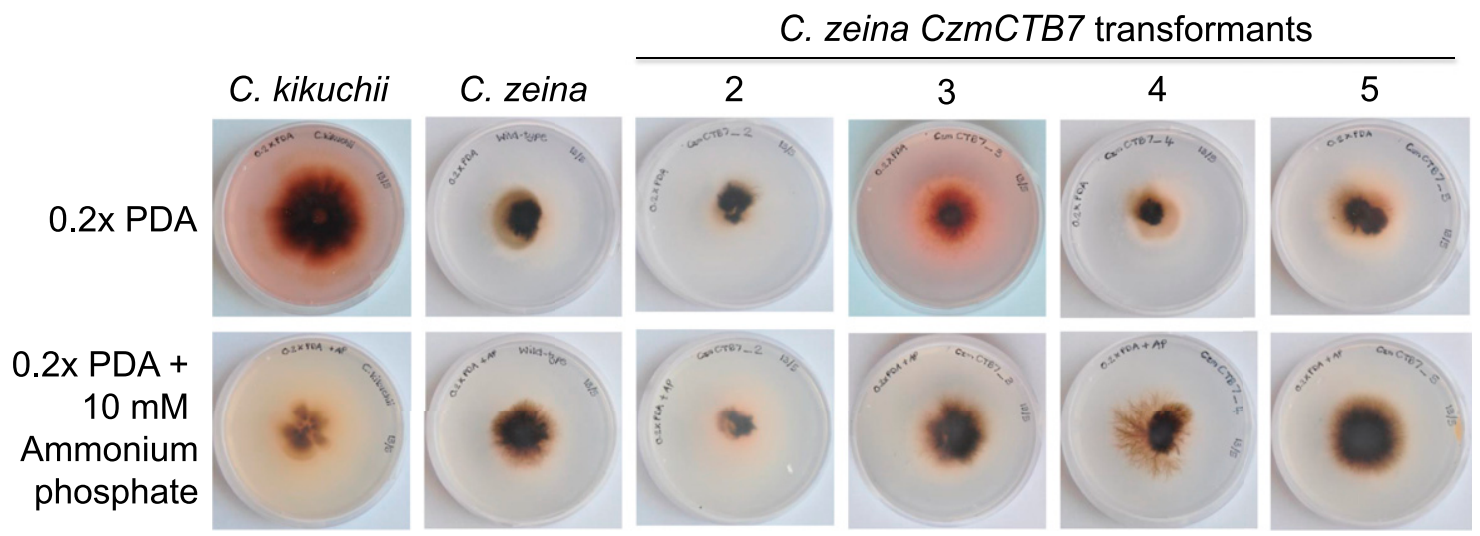

Fig. 8. Visual assessment of red pigment cercosporin production by Cercospora zeina CTB7 transformants complemented with the $C$. zeae-maydis CTB7 gene. Cultures were grown in constant light on cercosporin-conducive conditions $(0.2 \times$ potato dextrose agar [PDA], top panel) as well as cercosporin-suppressive conditions (0.2× PDA supplemented with $10 \mathrm{mM}$ ammonium phosphate, bottom panel). The positive control $C$. kikuchii culture and transformant 3 produced the red pigment cercosporin on $0.2 \times$ PDA, but the $C$. zeina wild-type culture and remaining transformants failed to do so. 
vegetative culture was maintained on $0.2 \times$ PDA $(3 \mathrm{~g}$ PDA, $12 \mathrm{~g}$ agar, and approximately $1,000 \mathrm{ml}$ of distilled water) and was used as a positive control for the cercosporin chemical analyses. Additional C. zeina and C. zeae-maydis isolates analyzed in this study are listed in Table 1.

Wild-type C. zeina was grown under seven separate in vitro growth conditions to generate material for RNA isolation and in vitro transcriptome sequencing. The seven growth conditions were: i) V8 agar, ii) $0.2 \times$ PDA supplemented with $10 \mathrm{mM}$ ammonium phosphate, iii) $\mathrm{PDA}, \mathrm{pH} 8[\mathrm{pH}$ adjusted with $\mathrm{Na}_{2} \mathrm{CO}_{3}+\mathrm{NaHCO}_{3}$ ], iv) PDA, $\mathrm{pH} 3$ [pH adjusted with citric acid $\left.+\mathrm{Na}_{2} \mathrm{HPO}_{4}\right]$, v) cornmeal agar, vi) complete medium $(10 \mathrm{~g}$ of glucose, $1 \mathrm{~g}$ of yeast extract, $1 \mathrm{~g}$ of casein hydrolysate, $1 \mathrm{~g}$ of $\mathrm{Ca}\left[\mathrm{NO}_{3}\right]_{2} \cdot 4 \mathrm{H}_{2} \mathrm{O}, 10 \mathrm{ml}$ of buffer solution $\left[2 \mathrm{~g}\right.$ of $\mathrm{KH}_{2} \mathrm{PO}_{4}, 2.5 \mathrm{~g}$ of $\mathrm{MgSO}_{4} \cdot 7 \mathrm{H}_{2} \mathrm{O}, 1.5 \mathrm{~g}$ of $\mathrm{NaCl}$, and approximately $100 \mathrm{ml}$ of distilled water] and approximately $1,000 \mathrm{ml}$ of distilled water), and vii) YPD ( $0.5 \mathrm{~g}$ of peptone, $0.5 \mathrm{~g}$ of yeast extract, $5 \mathrm{~g}$ of glucose, $18 \mathrm{~g}$ of $\mathrm{NaCl}$, and approximately $1,000 \mathrm{ml}$ distilled water). For growth conditions of the first group, the cultures were kept in constant darkness at ambient room temperature for 3 days. For growth conditions for groups ii through vii, the cultures were kept in constant light at $25^{\circ} \mathrm{C}$ for 7 days.

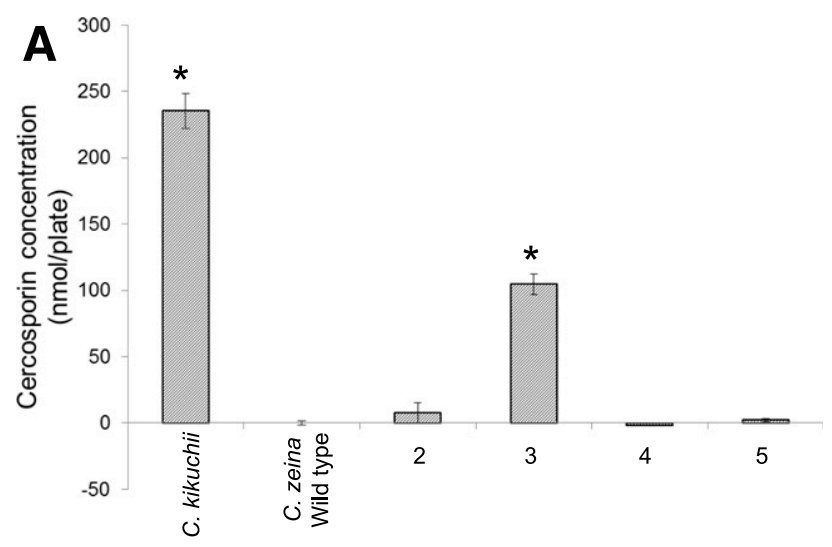

B

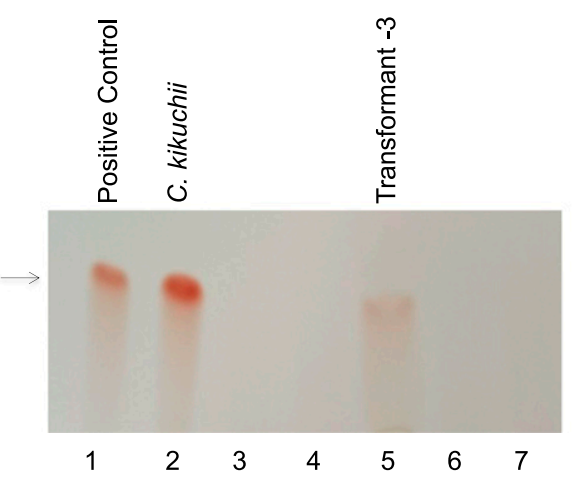

Fig. 9. Evaluation of cercosporin production by Cercospora zeina transformants with the $C$. zeae-maydis CTB7 gene. A, Cercosporin production was quantified using the $\mathrm{KOH}$ assay. Both $C$. kikuchii and transformant $3 \mathrm{dem}-$ onstrated significantly higher cercosporin concentrations than the wild-type C. zeina (one-way analysis of variance with a Tukey's multiple comparison test). The asterisks $(*)$ indicate concentrations significantly higher than the wild-type $C$. zeina concentrations at $P<0.05$. B, Thin-layer chromatography analysis of $C$. zeina transformant extracts, prepared using ethyl acetate. Compounds were separated using the ethyl acetate/hexane/methanol/ $\mathrm{H}_{2} \mathrm{O}(6$ : 4:1.5:1, vol/vol) solvent system. A pure cercosporin standard (lane 1) was visible as a red pigment at retention factor 0.45 (arrow). Cercosporin was present in the extract of $C$. kikuchii (lane 2) and transformant 3 (lane 5), but could not be detected in the $C$. zeina wild type (lane 3 ) and remaining transformants (lane 4, 6, and 7).
Maize inoculations with $C$. zeina.

The first glasshouse inoculation trial was conducted to generate GLS-infected B73 material for RT-qPCR following the methods described by Christie et al. (2017). C. zeina conidia were collected from V8 agar cultures and were used to artificially inoculate maize plants at the V12 growth stage, using the brush method (Meisel et al. 2009). The conidial suspension had a concentration of $1 \times 10^{6}$ conidia per milliliter. Inoculated leaf material (two leaves per plant) was harvested at five separate time points from three biological replicates, at $0 \mathrm{dpi}$, directly following inoculation, at $12 \mathrm{dpi}$, prior to lesion development, at $19 \mathrm{dpi}$, when rectangular GLS lesions were visible, at $21 \mathrm{dpi}$, when the GLS lesions started to coalesce, and at $25 \mathrm{dpi}$, when the leaves were blighted. The leaf material was flash-frozen in liquid nitrogen and was stored at $-80^{\circ} \mathrm{C}$ prior to DNA and RNA isolation. Subsequently, a second glasshouse trial was conducted in the same manner as described, with inoculated leaf material harvested at 32 dpi when rectangular GLS lesions were visible.

\section{RNA isolation and quality assessment.}

For transcriptome sequencing, RNA was isolated from in vitro-grown $C$. zeina cultures, using QIAzol lysis reagent (Qiagen), per the manufacturer's specifications. On-column DNase treatment and RNA purification was performed with the RNeasy mini kit (Qiagen). RNA quality was assessed using the Experion RNA StdSens system (Bio-Rad).

For RT-PCR, biological material was ground in liquid nitrogen and $100 \mathrm{mg}$ was used for RNA isolation with the RNeasy plant mini RNA extraction kit and the RNase-free DNase set for on-column DNA digestion (Qiagen), per the manufacturer's specifications. The High capacity RNA-to-cDNA kit (Applied Biosystems, Foster City, CA, U.S.A.) was used for cDNA synthesis, per the manufacturer's specifications.

\section{Transcriptome sequencing and expression analysis of $C$. zeina $C T B$ genes.}

Total RNA samples were submitted to BGI Tech Solutions Co., Ltd. (Beijing Genome Institute) for library construction and sequencing. RNA sequencing of 200-bp short-insert libraries was performed on an Illumina HiSeq 2000 platform (Illumina Inc.), with a 100-bp paired-end module for the seven in vitro $C$. zeina libraries.

Data filtering was done by BGI, which included the removal of adapters, low-quality reads, and reads with more than $5 \%$ unknown nucleotides. Read quality was evaluated, using FastQC, and 13 bases were removed from the beginning of each read in the sequencing files with fastx_trimmer from the FASTX Toolkit. Transcripts were assembled using Trinity (Grabherr et al. 2011) and were mapped to the C. zeina CMW25467 draft genome (Muller et al. 2016) with TopHat2 (Kim et al. 2013), using the default parameters. The standard deviation for the distribution on inner distances between read pairs was set at 200. The TopHat2 BAM output files were converted to the SAM file formant using SAMtools ( $\mathrm{Li}$ et al. 2009) and read coverage was counted with the htseq-count package (Anders et al. 2015), using the default parameters. Mapped reads were visualized using the Genome View tool (Abeel et al. 2012) and were used to validate the $C$. zeina $C T B$ gene annotations. $C$ zeina in vitro RNA-seq data have been deposited in the National Center for Biotechnology Information (NCBI) Gene Expression Omnibus database (accession number GSE90705).

\section{Maize field infection \\ with $C$. zeina and RNA-seq analysis of $C T B$ genes.}

Plants of maize inbred line B73 were subjected to natural infection with $C$. zeina at the Hildesheim Research Station, 
PANNAR SEED (Pty) Ltd., Greytown, KwaZulu-Natal. The material for RNA-seq analysis was the same as described by Christie et al. (2017), namely GLS-diseased lower leaves from three biological replicate plants at tasseling stage of development. RNA-seq analysis was conducted as described by Christie et al. (2017), except that the reads were simultaneously mapped to both the maize B73 genome sequence (v5b.60) (Schnable et al. 2009) and the C. zeina CMW25467 draft genome (Muller et al. 2016). Reads that mapped to the fungal genome were extracted and were used for read counting in the current study. In planta RNA-seq data have been deposited in the NCBI Gene Expression Omnibus database (accession number: GSE94442).

\section{$C T B$ gene annotation and expression analysis.}

The nucleotide sequences of the Cercospora nicotianae $C T B$ genes (Chen et al. 2007b) were retrieved from NCBI GenBank and were used to perform a BLASTn search against the draft genome assembly of $C$. zeina (Muller et al. 2016). The relevant contig was subjected to gene prediction using the AUGUSTUS (Stanke and Morgenstern 2005), FGENESH (Solovyev et al. 2006), and SNAP (Korf 2004) web-based gene prediction tools. The gene predictions were manually assessed and annotated using the GenomeView genome browser (Abeel et al. 2012). Manual annotation of the predicted C. zeina $C T B$ genes was done based on amino acid sequence alignments. The $C$. nicotianae $\mathrm{CTB}$ amino acid sequences were retrieved from GenBank and were used as query sequences in a BLASTp analysis against the $C$. zeae-maydis filtered model protein database (available from the Joint Genome Institute database) to identify predicted $C$. zeae-maydis CTB amino acid sequences. Pairwise protein sequences alignments were performed using EMBOSS Needle and multiple sequence alignments using MUSCLE 3.8. The annotated C. zeina $C T B$ gene cluster has been deposited in GenBank with the accession number KY656140.

\section{DNA isolation and PCR analysis.}

Small-scale fungal genomic DNA isolations were performed using a modified version of the CTAB method (Meisel et al. 2009). The ZR fungal/bacterial DNA mini isolation kit (Zymo Research, Irvine, CA, U.S.A.) was used, according to the manufacturer's specifications, for DNA isolation of the $C$. zeina $C z m C T B 7$ transformants. The CTB7del PCR was set up in a total volume of $12.5 \mu$, which consisted of: $1 \times$ KAPA2G Robust HotStart ReadyMix (Kapa Biosystems, Wilmington, MA, U.S.A.), $0.5 \mu \mathrm{m}$ of each primer, $0.6 \mu \mathrm{l}$ of dimethyl sulfoxide (DMSO), 25 ng of DNA, and sterile distilled water. The cycling conditions were as follows: $3 \mathrm{~min}$ at $95^{\circ} \mathrm{C}$, followed by 30 cycles of $30 \mathrm{~s}$ at $95^{\circ} \mathrm{C}, 30 \mathrm{~s}$ at $60^{\circ} \mathrm{C}$, and $1 \mathrm{~min}$ at $72^{\circ} \mathrm{C}$, with a final extension step of $72^{\circ} \mathrm{C}$ for $10 \mathrm{~min}$.
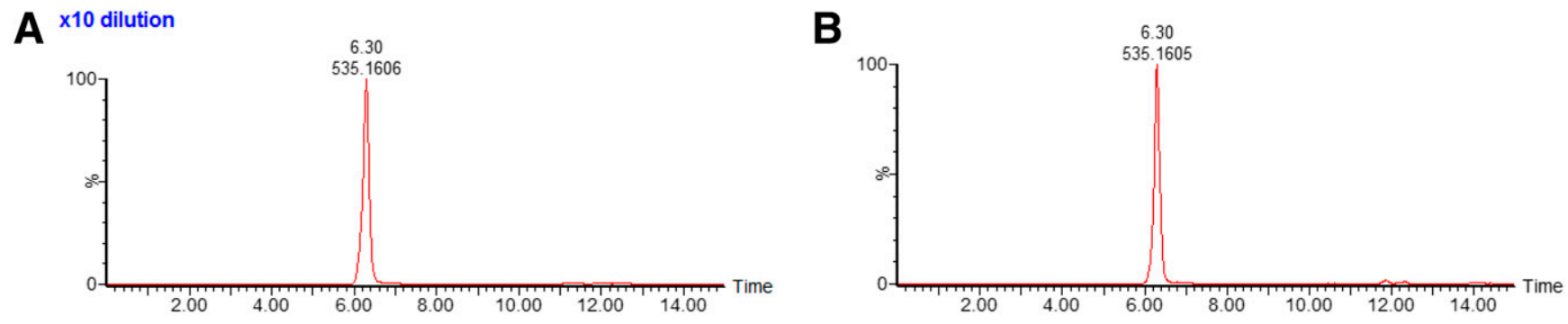

C $\times 10$ dilution

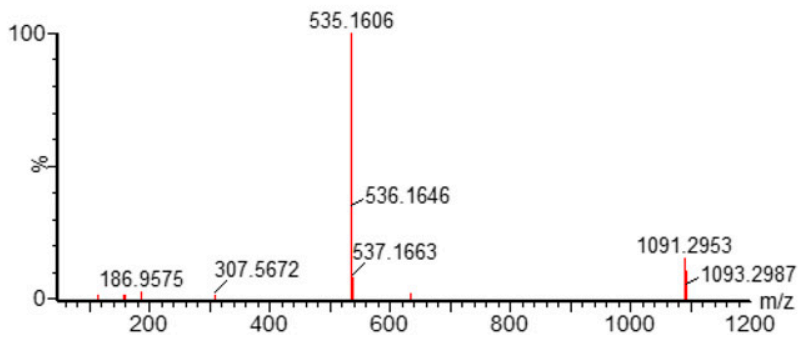

D

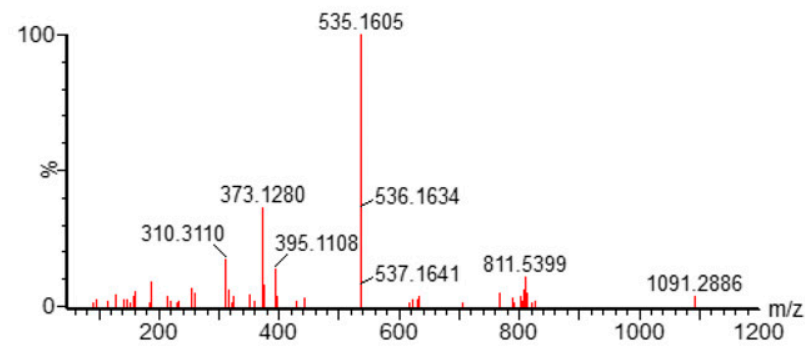

E $x 10$ dilution

$\mathbf{F}$
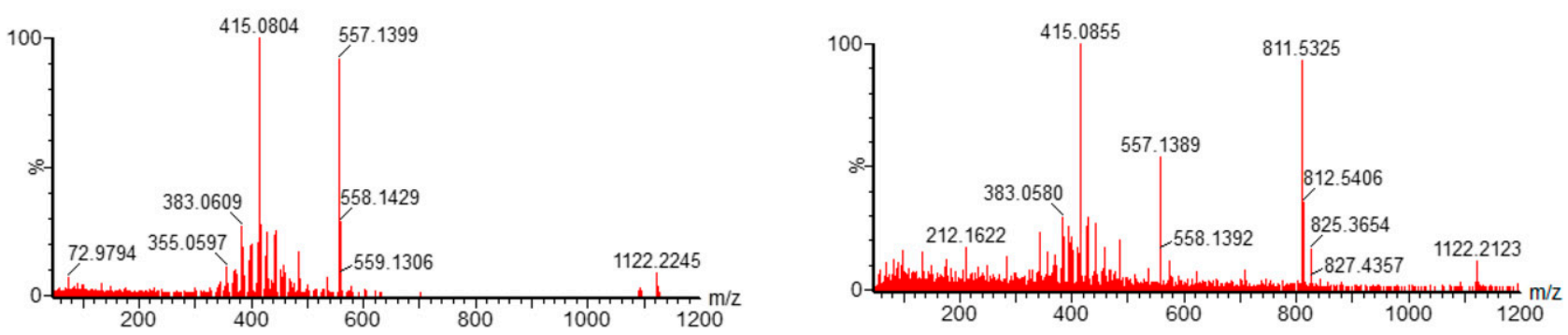

Fig. 10. Mass spectrometry confirms the presence of cercosporin in the extract from Cercospora zeina transformant 3 complemented with the C. zeae-maydis CTB7 gene. Samples were processed by ultra performance liquid chromatography-quadrupole-time-of-flight (TOF) mass spectrometry (MS), using a Synapt G2 high-definition MS system (Waters Inc.). The extracted ion chromatogram for $m / z 535.1604$ (the $\left[\mathrm{MH}^{+}\right]$calculated for cercosporin, $\mathrm{C}_{29} \mathrm{H}_{27} \mathrm{O}_{10}$ ) showed a peak at $6.30 \mathrm{~min}$ for both $\mathbf{A}$, the cercosporin standard and $\mathbf{B}$, the transformant 3 extract. High resolution mass spectra-electrospray ionization/atmospheric pressure chemical ionization-TOF of these peaks demonstrated an accurate mass-to-charge ratio $(\mathrm{m} / \mathrm{z})$ of $\mathbf{C}, 535.1606$ for the cercosporin standard and $\mathbf{D}$, 535.1605 for the transformant 3 extract, which is consistent with data previously described. The MS/MS spectrum of both $\mathbf{E}$, the cercosporin standard peak and $\mathbf{F}$, the transformant 3 extract peak demonstrated all of the main fragments previously described for cercosporin. 


\section{RT-PCR analysis.}

RT-PCR reactions were set up in a total volume of $12.5 \mu$, which consisted of: $1 \times$ KAPA2G Robust HotStart ReadyMix, $0.5 \mu \mathrm{m}$ of each primer, $0.6 \mu \mathrm{l}$ DMSO, $1 \mu \mathrm{l}$ of the cDNA, and sterile distilled water. The cycling conditions were as follows: $3 \mathrm{~min}$ at $95^{\circ} \mathrm{C}$ followed by 30 cycles of $15 \mathrm{~s}$ at $95^{\circ} \mathrm{C}, 15 \mathrm{~s}$ at $58^{\circ} \mathrm{C}$, and $30 \mathrm{~s}$ at $72^{\circ} \mathrm{C}$, and a final extension step of $72^{\circ} \mathrm{C}$ for $10 \mathrm{~min}$, with the following exceptions: 35 cycles for the CTB7 exon RT-PCR and an annealing temperature of $62^{\circ} \mathrm{C}$ for the EFl $\alpha$ RT-PCR.

The CTB7exon RT-PCR amplicon was cloned and sequenced using the InsTAclone PCR cloning kit (Thermo Fisher Scientific, Waltham, MA, U.S.A.), as per the manufacturer's specifications. Sequencing reactions were set up using the BigDye Terminator v3.1 cycle sequencing kit (Applied Biosystems), according to the manufacturer's guidelines, and were submitted to the DNA Sequencing Facility of the Natural and Agricultural Sciences Faculty at the University of Pretoria.

\section{Fungal quantification of inoculated maize leaves.}

DNA isolated from inoculated maize leaf material was used to quantify the in planta fungal load by means of a real-time PCR method as previously described (Korsman et al. 2010).

\section{RT-qPCR analysis.}

RT-qPCR analysis of the $C$. zeina $C T B$ genes (CTB1, CTB2, $C T B 7$, and $C T B 8$ ) was done according to the MIQE guidelines (Bustin et al. 2009), using the Bio-Rad CFX96 touch real-time PCR detection system. Primers were designed using the PrimerQuest Tool (Table 4). Expression was measured in three biological replicates. Reactions were set up in 10- $\mu$ l volumes, which consisted of $5 \mu$ of Lightcycler 480 SYBR green I master mix (Roche Diagnostics, Basel, Switzerland), $0.5 \mu \mathrm{M}$ of each of the primers, $1 \mu \mathrm{l}$ of cDNA template, and sterile distilled water. The cycling conditions used were: $95^{\circ} \mathrm{C}$ for $10 \mathrm{~min}, 45$ cycles of $95^{\circ} \mathrm{C}$ for $10 \mathrm{~s}, 60^{\circ} \mathrm{C}$ for $15 \mathrm{~s}$, and $72^{\circ} \mathrm{C}$ for $10 \mathrm{~s}$. Fluorescence was measured at the end of each elongation step and melt curve analysis was performed. Samples were normalized to the $40 \mathrm{~S}$ ribosomal protein $(40 S)$ and cytochrome c oxidase subunit III (Cyt III) reference genes. The expression stability of the reference genes were assessed using geNorm (Hellemans et al. 2007; Vandesompele et al. 2002). Relative quantification and normalization was performed using qBASE $^{\text {PLUS }}$ v1.0 (Hellemans et al. 2007). Statistical analyses were performed using GraphPad Prism v5.04 (GraphPad Software, Inc., La. Jolla, CA, U.S.A.).

\section{Heterologous expression of CTB7 \\ from C. zeae-maydis in C. zeina.}

Plasmid construction. A $1.8-\mathrm{kb}$ hygromycin-resistance cassette was PCR-amplified from pSilent1 (Nakayashiki et al. 2005), using the primer MCS HYG_XhoI F and HYG_BstEII R, and was cloned into $\mathrm{XhoI}$ and $B s t \mathrm{EII}$ restriction sites in the binary vector pCAMBIA-2301 (Cambia, Canberra, Australia). Similarly, a 1.8-kb green fluorescent protein (GFP) expression cassette was PCRamplified from pBR0073 (Ridenour et al. 2014), using the primer pair GFP_BamHI F and MCS GFP_BstEII R, and was cloned into BamHI and BstEII restriction sites in pCAMBIA2301 modified above. The resulting plasmid was designated pBYR14. Subsequently, CTB7 of $C$. zeae-maydis (open reading frame plus $1,473 \mathrm{bp}$ upstream of the predicted start codon and $604 \mathrm{bp}$ downstream of the predicted stop codon) was PCR-amplified from genomic DNA of the reference strain SCOH1-5 (Kim et al. 2011), using the primer pair XbaI-CTB7-F and BamHI-CTB7-RC, and was cloned into XbaI and BamHI restriction sites in $\mathrm{PBYR} 14$. The resulting plasmid was designated pBEA002.
Transformation of C. zeina. A. tumefaciens AGL-1 containing plasmid pBEA002 was grown at $28^{\circ} \mathrm{C}$ with shaking ( $250 \mathrm{rpm}$ ) for 3 days in $5 \mathrm{ml}$ of Luria broth, supplemented with carbenicillin $(50 \mu \mathrm{g} / \mathrm{ml})$ and kanamycin $(100 \mu \mathrm{g} / \mathrm{ml})$. The culture was diluted to an optical density at $600 \mathrm{~nm}\left(\mathrm{OD}_{600}\right)$ of 0.2 , using Agrobacterium induction medium (IAM) (Xue et al. 2013), and was incubated overnight at $28^{\circ} \mathrm{C}$ with shaking. The cultures were grown and diluted to an $\mathrm{OD}_{600}$ of 0.2 using IAM, to produce the induced (virulent) Agrobacterium stock. A conidial suspension of $C$. zeina was prepared by flooding V8 agar plates with IAM, dislodging the conidia with a glass spreader, and diluting to a concentration of $2 \times 10^{6} \mathrm{CFU} / \mathrm{ml}$. The induced Agrobacterium stock and conidial suspension was mixed in a $1: 1$ ( vol/vol) ratio and $200 \mu \mathrm{l}$ was plated onto a cellophane membrane overlain on IAM agar (18 g/liter) containing hygromycin B $(75 \mu \mathrm{g} / \mathrm{ml})$ and was incubated at $20^{\circ} \mathrm{C}$ for 3 days. Cellophane membranes were transferred to $0.2 \times$ PDA plates containing cefotaxime $(50 \mu \mathrm{g} / \mathrm{ml})$ and hygromycin B (SigmaAldrich, St. Louis) $(75 \mu \mathrm{g} / \mathrm{ml})$, to kill off Agrobacterium cells and select for transformants, respectively. Plates were incubated at room temperature for 14 days. Single conidia of putative transformants were transferred onto V8 plates containing the same concentrations of cefotaxime and hygromycin B and were subcultured weekly to maintain a sporulating culture.

Cercosporin extraction and chemical characterization. The C. zeina $C z m C T B 7$ transformants were cultured for approximately 2 months at ambient room temperature under constant light. Spectrophotometric quantification of cercosporin production was done using the $\mathrm{KOH}$ assay (Bluhm and Dunkle 2008; Yamazaki and Ogawa 1972). Absorbance measurements were taken for three plates per mutant and were normalized against the absorbance of the extract from a 0.2 $\times$ PDA with $10 \mathrm{mM}$ ammonium phosphate-grown culture. For TLC, extracts were prepared using ethyl acetate, as previously described (Dekkers et al. 2007), and an ethyl acetate/hexane/methanol/ $/ \mathrm{H}_{2} \mathrm{O}$ (6:4:1.5:1, vol/vol) elution solvent system (Choquer et al. 2005). Pure cercosporin (from Cercospora hayii [Sigma-Aldrich]) was dissolved in acetone $(1 \mathrm{mg} / \mathrm{ml})$ and was included as a standard.

Compound separation and detection was performed using a Waters Synapt G2 high definition mass spectrometry system (Waters Inc., Milford, MA, U.S.A.). The system is comprised of a Waters Acquity UPLC system hyphenated to a QTOF instrument. The extracts were injected (injection volume of 1 to $5 \mu \mathrm{l}$ ) onto a linear gradient of 5 to $95 \%$ solvent B over $15 \mathrm{~min}$ at $2.0 \mathrm{ml} / \mathrm{min}$ on a Kinetex EVO C18 column $(4.6 \mathrm{~mm} \times 50 \mathrm{~mm}, 17 \mu \mathrm{m}$ [Phenomenex, Torrence, CA, U.S.A.]). Solvent A was $0.1 \%$ formic acid in $\mathrm{H}_{2} \mathrm{O}$ and solvent $\mathrm{B}$ was acetonitrile. Chromatograms were extracted for $m / z 535.1604$ (Newman and Townsend 2016).

Data access. The sequence of the annotated C. zeina CTB gene cluster has been associated with NCBI GenBank BioProject PRJNA355276 and BioSample SAMN06067857 and is deposited in the DDBJ/EMBL/GenBank database under accession number KY656140. The raw in vitro and in planta RNA-seq sequence reads have been uploaded to the NCBI Gene Expression Omnibus database under accession numbers GSE90705 and GSE94442, respectively.

\section{ACKNOWLEDGMENTS}

This project was financed in part by the National Research Foundation (NRF) and Genomics Research Institute of University of Pretoria (UP). The grant holders acknowledge that opinions, findings, and conclusions or recommendations expressed in any publication generated by NRF-supported research are that of the authors and that the NRF accepts no liability whatsoever in this regard. This research was supported by a United States Department of Agriculture Norman E. Borlaug International Agricultural Science and Technology Fellowship, awarded to D. K. Berger. The authors wish to acknowledge the LC-MS facility (Chemistry Department, UP) and the glasshouse staff (Experimental Farm, UP). 


\section{LITERATURE CITED}

Abeel, T., Van Parys, T., Saeys, Y., Galagan, J., and Van de Peer, Y. 2012. GenomeView: A next-generation genome browser. Nucleic Acids Res. 40:e12.

Anders, S., Pyl, P. T., and Huber, W. 2015. HTSeq-A Python framework to work with high-throughput sequencing data. Bioinformatics 31:166-169.

Aragona, M., and Valente, M. T. 2015. Genetic transformation of the tomato pathogen Pyrenochaeta lycopersici allowed gene knockout using a splitmarker approach. Curr. Genet. 61:211-220.

Beseli, A., Amnuaykanjanasin, A., Herrero, S., Thomas, E., and Daub, M. E. 2015. Membrane transporters in self resistance of Cercospora nicotianae to the photoactivated toxin cercosporin. Curr. Genet. 61:601-620.

Bluhm, B. H., Dhillon, B., Lindquist, E. A., Kema, G. H., Goodwin, S. B., and Dunkle, L. D. 2008. Analyses of expressed sequence tags from the maize foliar pathogen Cercospora zeae-maydis identify novel genes expressed during vegetative, infectious, and reproductive growth. BMC Genomics 9:523.

Bluhm, B. H., and Dunkle, L. D. 2008. PHL1 of Cercospora zeae-maydis encodes a member of the photolyase/cryptochrome family involved in UV protection and fungal development. Fungal Genet. Biol. 45:1364-1372.

Bustin, S. A., Benes, V., Garson, J. A., Hellemans, J., Huggett, J., Kubista, M., Mueller, R., Nolan, T., Pfaffl, M. W., Shipley, G. L., Vandesompele, J., and Wittwer, C. T. 2009. The MIQE guidelines: Minimum information for publication of quantitative real-time PCR experiments. Clin. Chem. 55: 611-622.

Chen, H., Lee, M.-H., Daub, M. E., and Chung, K.-R. 2007b. Molecular analysis of the cercosporin biosynthetic gene cluster in Cercospora nicotianae. Mol. Microbiol. 64:755-770.

Chen, H.-Q., Lee, M.-H., and Chung, K.-R. 2007a. Functional characterization of three genes encoding putative oxidoreductases required for cercosporin toxin biosynthesis in the fungus Cercospora nicotianae. Microbiology 153:2781-2790.

Choquer, M., Dekkers, K. L., Chen, H.-Q., Cao, L., Ueng, P. P., Daub, M. E., and Chung, K.-R. 2005. The CTB1 gene encoding a fungal polyketide synthase is required for cercosporin biosynthesis and fungal virulence of Cercospora nicotianae. Mol. Plant-Microbe Interact 18 : 468-476.

Choquer, M., Lee, M.-H., Bau, H.-J., and Chung, K.-R. 2007. Deletion of a MFS transporter-like gene in Cercospora nicotianae reduces cercosporin toxin accumulation and fungal virulence. FEBS Lett. 581:489-494.

Christie, N., Myburg, A. A., Joubert, F., Murray, S. L., Carstens, M., Lin, Y.-C., Meyer, J., Crampton, B. G., Christensen, S. A., Ntuli, J. F., Wighard, S. S., Van de Peer, Y., and Berger, D. K. 2017. Systems genetics reveals a transcriptional network associated with susceptibility in the maize-grey leaf spot pathosystem. Plant J. 89:746-763.

Crous, P. W., and Braun, U. 2003. Mycosphaerella and its anamorphs: 1. Names published in Cercospora and Passalora. CBS Biodiversity Series Centraalbureau voor Schimmelcultures, Fungal Biodiversity Centre, Utrecht, The Netherlands.

Crous, P. W., Groenewald, J. Z., Groenewald, M., Caldwell, P., Braun, U., and Harrington, T. C. 2006. Species of Cercospora associated with grey leaf spot of maize. Stud. Mycol. 55:189-197.

Daub, M. E., and Chung, K.-R. 2009. Photoactivated perylenequinone toxins in plant pathogenesis. Pages 201-219 in: The Mycota, Vol. 5. H. B. Deising, ed. Springer, Heidelberg, Germany.

Daub, M. E., and Ehrenshaft, M. 2000. The photoactivated Cercospora toxin cercosporin: Contributions to plant disease and fundamental biology. Annu. Rev. Phytopathol. 38:461-490.

Dekkers, K. L., You, B.-J., Gowda, V. S., Liao, H.-L., Lee, M.-H., Bau, H.-J., Ueng, P. P., and Chung, K.-R. 2007. The Cercospora nicotianae gene encoding dual $O$-methyltransferase and FAD-dependent monooxygenase domains mediates cercosporin toxin biosynthesis. Fungal Genet. Biol. 44:444-454.

Dunkle, L. D., and Levy, M. 2000. Genetic relatedness of African and United States populations of Cercospora zeae-maydis. Phytopathology 90:486-490.

Fore, S. A., Daub, M. E., and Beute, M. K. 1988. Phytotoxic substances produced by some isolates of Cercospora arachidicola are not cercosporin. Phytopathology 78:1082-1086.

Gaur, M., Puri, N., Manoharlal, R., Rai, V., Mukhopadhayay, G., Choudhury, D., and Prasad, R. 2008. MFS transportome of the human pathogenic yeast Candida albicans. BMC Genomics 9:579.

Goodwin, S. B., Dunkle, L. D., and Zismann, V. L. 2001. Phylogenetic analysis of cercospora and mycosphaerella based on the internal transcribed spacer region of ribosomal DNA. Phytopathology 91:648-658.

Grabherr, M. G., Haas, B. J., Yassour, M., Levin, J. Z., Thompson, D. A., Amit, I., Adiconis, X., Fan, L., Raychowdhury, R., Zeng, Q., Chen, Z., Mauceli, E., Hacohen, N., Gnirke, A., Rhind, N., di Palma, F., Birren,
B. W., Nusbaum, C., Lindblad-Toh, K., Friedman, N., and Regev, A 2011. Full-length transcriptome assembly from RNA-seq data without a reference genome. Nat. Biotechnol. 29:644-652.

Hellemans, J., Mortier, G., De Paepe, A., Speleman, F., and Vandesompele, J. 2007. qBase relative quantification framework and software for management and automated analysis of real-time quantitative PCR data. Genome Biol. 8:R19.

Jenns, A. E., Daub, M. E., and Upchurch, R. G. 1989. Regulation of cercosporin accumulation in culture by medium and temperature manipulation. Phytopathology 79:213-219.

Kim, D., Pertea, G., Trapnell, C., Pimentel, H., Kelley, R., and Salzberg, S. L. 2013. TopHat2: Accurate alignment of transcriptomes in the presence of insertions, deletions and gene fusions. Genome Biol. 14:R36.

Kim, H., Ridenour, J. B., Dunkle, L. D., and Bluhm, B. H. 2011. Regulation of stomatal tropism and infection by light in Cercospora zeae-maydis: Evidence for coordinated host/pathogen responses to photoperiod? PLoS Pathog. 7:e1002113.

Korf, I. 2004. Gene finding in novel genomes. BMC Bioinformatics 5:59.

Korsman, J., Meisel, B., Kloppers, F., Crampton, B., and Berger, D. 2010. Quantitative phenotyping of grey leaf spot disease in maize using realtime PCR. Eur. J. Plant Pathol. 18:183-194.

Koshikumo, E. S. M., Alves, E., and Von Pinho, R. G. 2014. Induction and detection of toxin in Cercospora zeina and Cercospora sorghi f. sp. maydis. Braz. J. Agric. Sci. 9:31-35.

Kuyama, S., and Tamura, T. 1957. Cercosporin. A pigment of Cercosporina kikuchii Matsumoto et Tomoyasu. I. Cultivation of fungus, isolation and purification of pigment. J. Am. Chem. Soc. 79:5725-5726.

Lafontaine, I., and Dujon, B. 2010. Origin and fate of pseudogenes in Hemiascomycetes: A comparative analysis. BMC Genomics 11:260.

Li, H., Handsaker, B., Wysoker, A., Fennell, T., Ruan, J., Homer, N., Marth, G., Abecasis, G., and Durbin, R., 1000 Genome Project Data Processing Subgroup. 2009. The sequence alignment/map format and SAMtools. Bioinformatics 25:2078-2079.

Lu, Y., Xiao, S., Wang, F., Sun, J., Zhao, L., Yan, L., and Xue, C. 2017. Agrobacterium tumefaciens-mediated transformation as an efficient tool for insertional mutagenesis of Cercospora zeae-maydis. J. Microbiol. Methods 133:8-13.

Meisel, B., Korsman, J., Kloppers, F. J., and Berger, D. K. 2009 Cercospora zeina is the causal agent of grey leaf spot disease of maize in southern Africa. Eur. J. Plant Pathol. 124:577-583.

Muller, M. F., Barnes, I., Kunene, N. T., Crampton, B. G., Bluhm, B. H., Phillips, S. M., Olivier, N. A., and Berger, D. K. 2016. Cercospora zeina from maize in South Africa exhibits high genetic diversity and lack of regional population differentiation. Phytopathology 106:1194-1205.

Nakayashiki, H., Hanada, S., Nguyen, B. Q., Kadotani, N., Tosa, Y., and Mayama, S. 2005. RNA silencing as a tool for exploring gene function in ascomycete fungi. Fungal Genet. Biol. 42:275-283.

Newman, A. G., and Townsend, C. A. 2016. Molecular characterization of the cercosporin biosynthetic pathway in the fungal plant pathogen Cercospora nicotianae. J. Am. Chem. Soc. 138:4219-4228.

Reid, I., O'Toole, N., Zabaneh, O., Nourzadeh, R., Dahdouli, M., Abdellateef, M., Gordon, P. M., Soh, J., Butler, G., Sensen, C. W., and Tsang, A. 2014. SnowyOwl: Accurate prediction of fungal genes by using RNA-Seq and homology information to select among ab initio models. BMC Bioinformatics 15:229.

Rep, M., Duyvesteijn, R. G. E., Gale, L., Usgaard, T., Cornelissen, B. J. C., Ma, L.-J., and Ward, T. J. 2006. The presence of GC-AG introns in Neurospora crassa and other euascomycetes determined from analyses of complete genomes: Implications for automated gene prediction. Genomics 87:338-347.

Ridenour, J. B., Smith, J. E., Hirsch, R. L., Horevaj, P., Kim, H., Sharma, S., and Bluhm, B. H. 2014. UBL1 of Fusarium verticillioides links the $\mathrm{N}$-end rule pathway to extracellular sensing and plant pathogenesis. Environ. Microbiol. 16:2004-2022.

Schnable, P. S., Ware, D., Fulton, R. S., Stein, J. C., Wei, F., Pasternak, S., Liang, C., Zhang, J., Fulton, L., Graves, T. A., Minx, P., Reily, A. D., Courtney, L., Kruchowski, S. S., Tomlinson, C., Strong, C., Delehaunty, K., Fronick, C., Courtney, B., Rock, S. M., Belter, E., Du, F., Kim, K. Abbott, R. M., Cotton, M., Levy, A., Marchetto, P., Ochoa, K., Jackson, S. M., Gillam, B., Chen, W., Yan, L., Higginbotham, J., Cardenas, M., Waligorski, J., Applebaum, E., Phelps, L., Falcone, J., Kanchi, K., Thane, T., Scimone, A., Thane, N., Henke, J., Wang, T., Ruppert, J., Shah, N., Rotter, K., Hodges, J., Ingenthron, E., Cordes, M., Kohlberg, S., Sgro, J., Delgado, B., Mead, K., Chinwalla, A., Leonard, S., Crouse, K., Collura, K., Kudrna, D., Currie, J., He, R., Angelova, A., Rajasekar, S., Mueller, T., Lomeli, R., Scara, G., Ko, A., Delaney, K., Wissotski, M., Lopez, G., Campos, D., Braidotti, M., Ashley, E., Golser, W., Kim, H., Lee, S., Lin, J., Dujmic, Z., Kim, W., Talag, J., Zuccolo, A., Fan, C., Sebastian, A., 
Kramer, M., Spiegel, L., Nascimento, L., Zutavern, T., Miller, B., Ambroise, C., Muller, S., Spooner, W., Narechania, A., Ren, L., Wei, S., Kumari, S., Faga, B., Levy, M. J., McMahan, L., Van Buren, P., Vaughn, M. W., Ying, K., Yeh, C.-T., Emrich, S. J., Jia, Y., Kalyanaraman, A., Hsia, A.-P., Barbazuk, W. B., Baucom, R. S., Brutnell, T. P., Carpita, N. C., Chaparro, C., Chia, J.-M., Deragon, J.-M., Estill, J. C., Fu, Y., Jeddeloh, J. A., Han, Y., Lee, H., Li, P., Lisch, D. R., Liu, S., Liu, Z., Nagel, D. H., McCann, M. C., SanMiguel, P., Myers, A. M., Nettleton, D., Nguyen, J., Penning, B. W., Ponnala, L., Schneider, K. L., Schwartz, D. C., Sharma, A., Soderlund, C., Springer, N. M., Sun, Q., Wang, H., Waterman, M., Westerman, R., Wolfgruber, T. K., Yang, L., Yu, Y., Zhang, L., Zhou, S., Zhu, Q., Bennetzen, J. L., Dawe, R. K., Jiang, J., Jiang, N., Presting, G. G., Wessler, S. R., Aluru, S., Martienssen, R. A., Clifton, S. W., McCombie, W. R., Wing, R. A., and Wilson, R. K. 2009. The B73 maize genome: Complexity, diversity, and dynamics. Science 326:1112-1115.

Shim, W. B., and Dunkle, L. D. 2003. CZK3, a MAP kinase kinase kinase homolog in Cercospora zeae-maydis, regulates cercosporin biosynthesis, fungal development, and pathogenesis. Mol. Plant-Microbe Interact 16:760-768.

Solovyev, V., Kosarev, P., Seledsov, I., and Vorobyev, D. 2006. Automatic annotation of eukaryotic genes, pseudogenes and promoters. Genome Biol. 7 (Suppl 1):S10.

Staerkel, C., Boenisch, M. J., Kröger, C., Bormann, J., Schäfer, W., and Stahl, D. 2013. $C b C T B 2$, an $O$-methyltransferase is essential for biosynthesis of the phytotoxin cercosporin and infection of sugar beet by Cercospora beticola. BMC Plant Biol. 13:50.

Stanke, M., and Morgenstern, B. 2005. AUGUSTUS: A web server for gene prediction in eukaryotes that allows user-defined constraints. Nucleic Acids Res. 33:W465-W467.

Upchurch, R. G., Walker, D. C., Rollins, J. A., Ehrenshaft, M., and Daub, M. E. 1991. Mutants of Cercospora kikuchii altered in cercosporin synthesis and pathogenicity. Appl. Environ. Microbiol. 57:2940-2945.

Vandesompele, J., De Preter, K., Pattyn, F., Poppe, B., Van Roy, N., De Paepe, A., and Speleman, F. 2002. Accurate normalization of real-time quantitative RT-PCR data by geometric averaging of multiple internal control genes. Genome Biol. 3:research0034.
Wang, J., Levy, M., and Dunkle, L. D. 1998. Sibling species of cercospora associated with gray leaf spot of maize. Phytopathology 88:1269-1275.

Ward, J. M. J., Stromberg, E. L., and Nutter, F. W. 1999. Grey leaf spot: A disease of global importance in maize production. Plant Dis. 83 884-895.

Weiland, J. J., Chung, K. R., and Suttle, J. C. 2010. The role of cercosporin in the virulence of Cercospora spp. to plant hosts. Pages 109-117 in: Cercospora Leaf Spot of Sugar Beet and Related Species. L. T. Lartey, J. J. Weiland, L. Panella, P. W. Crous, and C. E. Windels, eds. The American Phytopathological Society, St. Paul, MN, U.S.A.

Xue, C., Wu, D., Condon, B. J., Bi, Q., Wang, W., and Turgeon, B. G. 2013. Efficient gene knockout in the maize pathogen Setosphaeria turcica using Agrobacterium tumefaciens-mediated transformation. Phytopathology 103:641-647.

Yamazaki, S., and Ogawa, T. 1972. The chemistry and stereochemistry of cercosporin. Agric. Biol. Chem. 36:1707-1718.

You, B.-J., Lee, M.-H., and Chung, K.-R. 2008. Production of cercosporin toxin by the phytopathogenic Cercospora fungi is affected by diverse environmental signals. Can. J. Microbiol. 54:259-269.

Zhang, Z., and Gerstein, M. 2004. Large-scale analysis of pseudogenes in the human genome. Curr. Opin. Genet. Dev. 14:328-335.

\section{AUTHOR-RECOMMENDED INTERNET RESOURCES}

Cambia website: http://www.cambia.org/daisy/cambia/585

EMBOSS Needle: http://www.ebi.ac.uk/Tools/psa/emboss_needle

FastQC database: http://www.bioinformatics.babraham.ac.uk/projects/ fastqc

FASTX toolkit: http://hannonlab.cshl.edu/fastx_toolkit/index.html

Joint Genome Institute database: http://genome.jgi.doe.gov/Cerzm1/ Cerzm1.home.html

MUSCLE 3.8 database: http://www.ebi.ac.uk/Tools/msa/muscle

PrimerQuest tool: http://www.idtdna.com/PrimerQuest/Home 